PILOT STUDY: INVESTIGATING CHILD LIFE SUPPORT SESSIONS AS A TOOL FOR RETINOPATHY OF PREMATURITY INFANTS UNDERGOING ROP EYE EXAMS

By

Morgan Livingstone CCLS CIMI

\begin{abstract}
A Major Research Paper
Presented to Ryerson University

In partial fulfillment of the requirements for the degree of

Masters of Arts in the program of Early Childhood Studies
\end{abstract}

Toronto, Ontario, Canada 2008

CMorgan Livingstone 2008 


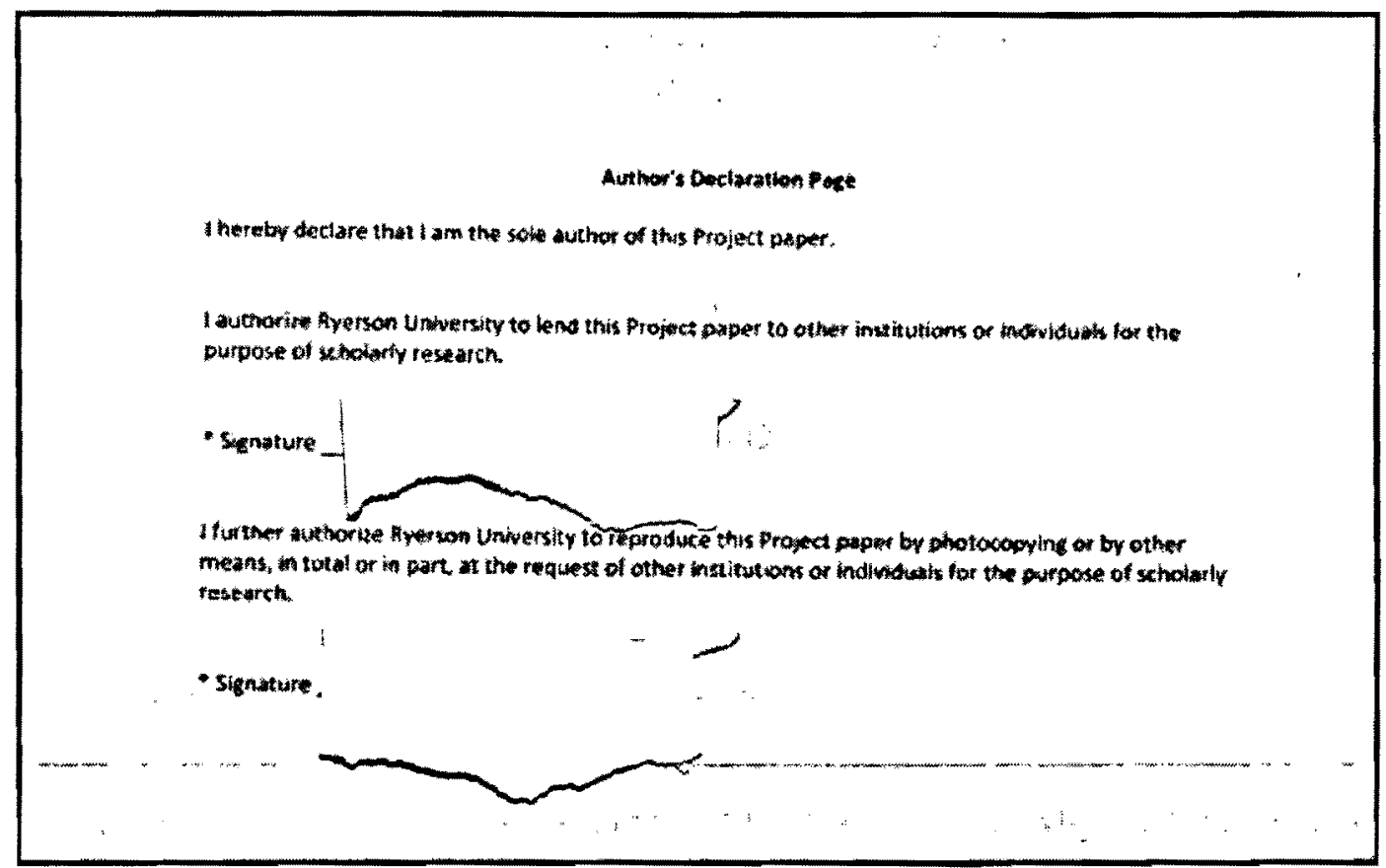




\title{
PILOT STUDY: INVESTIGATING CHILD LIFE SUPPORT SESSIONS AS A TOOL FOR RETINOPATHY OF PREMATURITY INFANTS UNDERGOING ROP EYE EXAMS
}

(CMorgan Livingstone 2008

Master of Arts

Early Childhood Studies

Ryerson University

\begin{abstract}
The aim of this study was to assess the coping of premature infants during ROP eye exams both before and after receiving 3 child life support sessions. This assessment used the adapted COMFORT behavior scale as a reliable and validated standardized assessment tool. An experienced ROP clinic nurse and a clinic fellow made paired observations during 2 routine ROP eye exams to record infant coping. 9 infants were consented into the study and 2 infants were found to be at risk for ROP and therefore continued in the study. The other 7 infants were found to be not at risk. The results of the pre and post test coping results demonstrated a drop in distress and an increase in each infants coping during the ROP eye exam. The results suggest that Child Life support sessions do increase and enhance premature infant coping during ROP eye exams.
\end{abstract}




\section{Table of Contents}

Authors Declaration

ii

Abstract

iii

Table of Contents

iv

List of Tables

vi

List of Figures

vii

List of Appendices

viii

Chapter 1: Introduction

1

Chapter 2: Literature Review

3

The field of Child Life, its origins, mission, roles and purpose

3

Child Life practices and supportive strategies for children during painful procedures

5

Current assessment tools and/or scales used to assess coping in infants during painful procedures.

Theoretical framework

Chapter 3: Methodology

Research Question

Hypothesis

Operational Definitions

Scope

Design

Setting

Sampling Procedure

Ethical Issues

Assessment and intervention timeline

Data Collection/Assessment scale

Ethical Issues in Data Collection 
$\begin{array}{ll}\text { Data Organization } & 26\end{array}$

Data Analysis and Interpretation $\quad 26$

$\begin{array}{lr}\text { Chapter 4: Session Procedures } & 27\end{array}$

$\begin{array}{lr}\text { Chapter 5: Results } & 30\end{array}$

$\begin{array}{lr}\text { Chapter 6: Discussion } & 37\end{array}$

$\begin{array}{ll}\text { Limitations } & 39\end{array}$

Recommendations/ Future Research $\quad . \quad 40$

$\begin{array}{ll}\text { Conclusion } & 41\end{array}$

References $\quad 43$ 


\section{List of Tables}

Table 1 Initial assessment scores by ROP nurse

Table 2 Initial assessment scores by clinic fellow

Table 3 Pre-test measures only correlations

32

Table 4 Nurse and fellow pre/post test scores for study infants $1 \mathrm{c}$ and $1 \mathrm{i}$

$33-36$ 


\section{List of Figures}

Figure 1 Present interaction

Figure 2 Research study interaction 
List of Appendices

Appendix A. Comfort Scale

Appendix B. Session Outline

Appendix C. Telephone script

Appendix D. Information Package - Study Profile

Appendix E. Consent Form Letter

Appendix F. Ethics Approval Letters - Ryerson

- Sick Kids 
Chapter 1: Introduction:

In any ecological system illness creates stress (Ambuel, Hamlet, Marx, \& Blumer, 1992). The ability to cope with the stresses caused by illness is important to survival and is also a foundation for growth and change in human development (Gardiner \& Kosmitzki, 2008). Each newborn has an individual set of orienting and coping strategies they use to manage their interactions. The organization of these strategies is the infant's early coping style. This coping style will continue to develop and change as the infant grows (Williamson, Zeitlin, \& Szczepanski, 1989). Pearlin and Schooner (1987) describe coping efforts as "specific actions, overt or covert, which are utilized in specific situations with the intention of reducing stress" (p. 339). Historically, nonpharmacologic supportive interventions for infant coping needs during painful medical procedures have been neglected (Noll \& Kulkarni, 1989). The field of Child Life provides supportive intervention and techniques that assist and promote coping in children of all ages. However there is no best practice standard of Child Life interventions and supportive care focused on the specific needs of infants during hospitalization and painful procedures at present.

Infants have basic human rights to assistance in coping that helps them manage pain and stressful situations. These rights were created to ensure that all children receive best medical care and practices available. The UN Convention on the Rights of the Child (CRC) in child friendly language (Unicef,1990) Article 19 states, "You have the right to be protected from being hurt and mistreated, in body or mind". Article $\mathbf{2 4}$ states, "You have the right to the best health care possible, safe water to drink, nutritious food, a clean and safe environment, and information to help you stay well". Article 39 states "You have the right to help if you have been hurt, neglected or badly treated". These CRC statements illustrate that the lack of coping support through therapeutic interventions is a gross 
violation of an infant's basic human rights. Although the ideal approach to address the issue of infant pain would be to eliminate pain by preventing painful intervention, this is not realistic in the course of an infant's life saving medical experience. Therefore, appropriate interventions are necessary to minimize pain and assist an infant's coping (Stevens, Gibbins, \& Frank, 2003). Early childhood illness and repeated medical procedures can have a negative effect on a child's healthy growth and development, and cause maladaptive adjustment and coping, poor coping and self soothing (Hicks \& Lavender, 2001). Studies of infant distress have concluded that infants seem to undergo significant distress during the retinopathy of prematurity (ROP) eye examinations (Halliday, 2006). Ophthalmologists should take into consideration the infant's discomfort caused by physical manipulation of the eyes and attempt to perform the examination as swiftly, yet safely, as possible using topical anesthetic and saline drops (Rush, Rush, Nicolau, Chapman, \& Naqvi, 2004). Numerous studies suggest a mix of support techniques will better assist infants in coping with similar pain during procedures such as routine heel sticks and suctioning (Mitchell, Brooks, \& Roane, 2000; Stevens et. al. 2003).

This pilot study will examine the existing coping process of infants undergoing initial ROP eye exams, and then examine the impact of Child Life supportive techniques on the same infants coping competence during future ROP eye exams. The research hypothesis is that the Child Life support sessions provided to infants and parents will increase and improve infant coping during painful procedures. By doing so, the hope is to alleviate, eliminate and avoid potentially harmful maladaptive coping and prevent potential coping problems in the infant's future healthy development. 
Chapter 2: Literature review:

A review of the current literature was undertaken. A large number of articles on current child life practice and supportive interventions were reviewed and selected for inclusion. The large numbers of original articles included in the search were sorted to exclude outdated practices, interventions specifically for older children and youths, repetition and non-empirical literature. The focus was on the field of Child Life and the supportive interventions that increase and enhance a child's coping provided by Certified Child Life Specialists (CCLS) in practice with infants and young children (0-12 months) undergoing painful procedures.

This review will focus on four areas in the literature:

The field of Child Life, its origins, mission, roles and purpose.

Child Life practices and supportive strategies for children during painful procedures.

Current assessment tools and/or scales used to assess coping in infants during painful procedures.

Theoretical framework

The field of Child Life:

Child Life programs have become a standard in modern health care, in children's hospitals, adult hospitals, acute and chronic care hospitals, and in non-traditional alternative settings providing support. to children coping with illness, loss, trauma and palliative care (American Academy of Pediatrics, 2000). Child Life programs in adult hospitals include educating and supporting children of adult patients throughout the diagnosis, treatment and recovery or palliative stages. Child Life support following a loss 
includes fostering coping and positive grieving through a wide range of loss: loss of a limb or body part, loss of ability following an acquired brain injury, traumatic brain injury or illness, and the loss of a family member, friend or pet.

Since the early 1920's the Child Life profession has grown and developed as a means of improving children's health care experiences through the use of play and psychosocial supportive interventions. In the early years of the profession, play, preparation and educational programs were provided to children, and advocacy for family centred care began. Between 1965 and 1967 a group of women formally established the Association for the Care of Children's Health (ACCH ). By 1982 the Child Life Council ( $\mathrm{CLC}$ ) was established from within the $\mathrm{ACCH}$ and a decade of research and work began on professional development, standards of clinical practice and a clinical practice manual (Child Life Council, 2002). Certification and the standards of practice for the Child Life profession became the focus for judgment of appropriate care, and a noted issue in the management of risk (Kleinberg, 1987). Professional certification was adopted in 1998 by means of a standardized child life certification exam. The Canadian Association of Child Life Leaders (CACLL) is an association of Child Life leaders from across Canada and is closely affiliated and supports the CLC certification process and government of the field of Child Life.

CCLS are now recognized as essential professional members of interdisciplinary health care teams (American Academy of Pediatrics, 2000). Presently the role of a CCLS is defined as an expert in child development, who promotes effective coping in children through the use of therapeutic play, procedural preparation, medical education, and feeling focused expressive activities (Child Life Council, 2006, p.54). This statement does not include an important additional aspect of the Child Life role which is in providing distraction techniques during painful procedures. Hicks and Lavender (2001) identify CCLS 
supports as a means of assisting young children in learning positive coping techniques.

The CLC's Position Statement on Child Life Services in Healthcare Settings (2006) indentified two essential goals of child life services: "A. To assess coping responses and needs of children and families to healthcare experiences"; and "B. To minimize stress and anxiety for the child" (p. 1757). The inclusion of these important goals highlights the child life specialist's role in providing interventions that increase and enhance a child's coping during painful procedures.

Clearly missing in the Child Life literature was specific guidelines and statements about Child Life theoretical foundations of practice with infants. All official documents of the CLC generalized child life specialist's work to include infants, children, youth and families.

Child life practices, supportive interventions during painful procedures, and assessment of these interventions:

Common Child Life supportive practices to assist a child's coping during painful procedures used regularly by the author and practicing CCLS include positioning for comfort, distraction, infant massage, medical play, breathing/blowing exercises, guided imagery and meditation. Of these practices the cognitive and complementary strategies, such as medical play, breathing/blowing exercises, guided imagery and meditation were excluded for use in the author's proposed research study because they are not appropriate for the focus population of 0-12months. Mitchell \& Brooks (2000) and Kuhn, Schanberg, Field, Symanski, Zimmerman, Scafidi \& Roberts (1991) use formal assessment tools to assess the validity of supportive interventions for infants coping during painful procedures. Some of the assessment tools require physiological measures, and as such are not assessment tools being considered for use in this research study. The use of these tools reflects each articles thorough analysis and 
evaluation of the supportive techniques being provided to infants in pain.

Infant Specific Interventions:

Infants in the neonatal intensive care unit experience painful procedures throughout each day. Gibbins, (2007) highlights that inverse relation between the increased number of procedures for those infants that are more premature and more severely ill. Ueda \& Caulfield (2001) identify CCLS as an important addition to the interdisciplinary pediatric health care team in the management of medically fragile infants. While discussing the pivotal role of Child Life in the delivery of health related services, this article highlights the fact that young children receiving Child Life support in the intensive care unit show significantly less emotional distress, more effective coping and better post hospital adjustment than children who did not receive Child Life care. These infant specific Child Life interventions include swaddling, positive touch and infant massage, and education for family involvement in the Neonatal Intensive Care Unit (NICU). CCLS are now routinely included in interdisciplinary pain management teams implementing new pain management standard strategies for pre and post operative procedural pain (Jordan-Marsh, Hubbard, Watson, Hall, Miller, \& Mohan, 2004; Blount, Piira, Cohen, \& Cheng, 2006). Similarly, the NICU physical and social environments are recognized as factors that impact infant coping and adaptation (Warren, 2002). Moving past the traditional views of environment, such as colour, layout and room size, Warren (2002) encourages practitioners to consider the temporal, social, cultural and organizational factors that mediate physical properties and relationships, all which affect an infant's experience in the NICU environment. Many of the Child Life and nursing strategies facilitating infant adaptation include physical environment factors, such as lighting, the use of soft textures in bedding and noise controlling strategies. Current best practices include close infant interactions which positively affect coping and adaptation. These best practice interactions are individualized care, with regard to" 
preferred positioning, improved parent infant interactions, the introduction of music or massage therapy, and the addition of personal items. The need for individualized care impacts common practice routines that may suit some infants some of the time, but not all infants all of the time.

The role of Child Life in the management of pediatric pain during painful procedures is not well documented in current research, although the use of nonpharmacological pain management strategies is a common expectation in everyday child life practice (Bandstra et al. 2008). A recent online survey of CCLS in existing Child Life programs across North America gathered information about a range of pain support strategies employed in current practice. The four broad areas of nonpharmacological strategies included in the survey were Behavioral, Cognitive, Complementary and Physical (Bandstra et al. 2008). Demographic and descriptive information from those sampled was collected for the consideration of personal and professional characteristics. In relation to this literature review, important survey findings were that only $1.2 \%$ of CCLS surveyed were primarily working in the NICU, and only $0.7 \%$ work primarily - with neonates 0-1 month of age. However, of the CCLS surveyed, $25.9 \%$ indicated that they work primarily with children ranging in age from 2 months to 12 years of age (Bandstra et al.2008), at least a : small portion of the target age group. One interesting finding in the use of Child Life practices specifically discussed in the literature was the high use of behavioral distraction as a strategy, and reports that the use of distraction has strong empirical support (Bandstra et al. 2008). Other findings included the average use of music as a complementary strategy, and slightly above average use of comfort positioning as a physical strategy. Both music and positioning were found to have mixed empirical support. A disappointing finding from this survey included the low frequency of use of the physical strategies, healing and therapeutic touch and massage. Massage was reported to have some mixed empirical support, but healing and therapeutic touch was rated not effective (Bandstra et al. 
2008). Concluding suggestions by Bandstra et al. (2008) include the formation of Child Life training opportunities to increase skill and knowledge as a means of encouraging the implementation of newer, less known interventions that are well supported in literature, as demonstrated in this literature review.

Field (1986) described a number of common practice early interventions for premature infants. Beyond the environmental factors investigated by Warren (2002), Field focused on studies of supplemental stimulations. Those investigated included auditory, non nutritive sucking, tactile/kinesthetic/vestibular stimulation including various combinations and multimodal stimulations of tactile, auditory, visual and social stimulations. Field (1986) found that adaptations of routine procedures, the use of soothers during feedings and painful procedures, stroking stimulation (infant massage), and parent training, were among the most cost effective early interventions that prove effective for premature infants and enhance growth, coping, behavioral gains, motor activity and alertness.

Building on these earlier recommendations, Mitchell \& Brooks (2000) includes the use of a soother (non nutritive sucking) as one of 4 nonpharmacological interventions for pain in premature infants. The other interventions considered, that were not included in Field (1986) are containment, environmental factors and sucrose as an analgesic. By closely monitoring infants in pain, major indicators of pain were also identified in this article, including facial grimaces and physiological parameters (heart rate and oxygen saturation). Looking more closely at each of the 4 identified nonpharmacological interventions for pain, containment through gentle swaddling was found to reduce stress and facilitate more rapid recovery following painful procedures. Nonnutritive sucking studies failed to conclusively identify if it was the process of sucking that helps to reduce the pain, or whether sucking merely helps an infant remain calm during painful procedures. Regardless of ambiguous results, 
the soother is identified as a valuable tool in assisting premature infants in self regulation and coping.

Environmental factor studies assessed by Mitchell \& Brooks (2000) suggest that a stable, supportive environment, with low noise, dim lights and minimal touching lead to increased coping and decreased stress. Minimal touching as a means of fostering coping is in direct conflict with Field (1986) who suggests that infant massage/positive touch benefits infants coping. These conflicting results highlight the need for further evidence-based practice investigation, and noting that each individual infant may have a different need for increased positive touch or minimal touch. This individual need would have to be assessed during the initial child life session for treatment planning.

Oral sucrose as an analgesic is presented as the final strategy for procedural pain management in premature infants. The suggestion for best practice includes combining oral sucrose with other nonpharmacologial pain reduction measures. In a follow up study, Mitchell \& Brooks (2003) continue with further research into the benefits of oral sucrose. This investigation focuses on a consensus statement made by the International Evidence-Based Group for neonatal pain for the prevention and management of pain in newborns. Guidelines included the combination of behavioral and pharmacologic interventions for optimal effect. The authors conclude the practice of providing a soother with sucrose should be one of many interventions and comfort methods provided to infants undergoing painful procedures. This review of studies evaluating pain relief includes some preliminary information about the different pain scales, coding systems and profiles commonly used in infant pain assessment, such as the Premature Infant Pain Profile (PIPP) and the Neonatal Facial Coding System (NFCS). These and various other infant pain and/or coping assessment tools will be examined in greater depth further into this literature review. 
Positioning for comfort:

Positions of comfort for children are a common supportive practice for CCLS when working with a child undergoing a painful procedure. The provision of tactile-kinesthetic stimulation in preterm infants was studied by Kuhn, Schanberg, Field, Symanski, Zimmerman, \& Roberts (1991) and assessed the benefits of positioning infants in the supine and prone positions when providing this stimulation at set times over a 10 day period. The overall results of this study were positive, proving that tactilekinesthetic stimulation and positioning for comfort increases coping, and enhanced weight gain and development in preterm infants, but the different assessment tools included in this study to determine these results were focused more on the neuroendocrine system and results. These physiological assessment tools place it outside of the skill area of common practice concerns of a CCLS, who is able to assess the behavioral and visual cues of an infant's coping with their current training.

Infant Massage:

Recent literature reviewed for this paper points to greater professional interest and appreciation of infant massage as an evidence based practice coping mechanism for reducing stress in hospitalized infants (Beaumont, 2005; Zealy, 2005; Harrison, 2001; Hernandez, et al. 2007). In the past it was identified that many health care professionals disregarded or undervalued infant massage as a pain reduction strategy in infant procedural support is because much of the earlier published research were unsystematic reviews, general discussion pieces and non-randomized, uncontrolled trials (Zealey, 2005). In a systematic review of the literature Zealey determines a number of benefits of infant massage in the care of infants with specific medical needs, but finds there is insufficient evidence found for the continued practice of massaging infants in the NICU that are preterm and low birth weight. In contrast, 
Harrison (2001) deduced that an infant's physiological stability is a factor in the successful outcomes and benefits of infant massage. Fragile, unstable infants receiving stroking massage may show increases in stress levels, and would benefit more from still, gentle touch or resting hands to promote comfort. Findings on stroking massage, alone or in combination with additional physical stimulation concluded that this type of massage has an immediate positive effect on coping and a reduction in behavioral distress in infants that are stable (Harrison, 2001; Hernandez-Reif, 2007).

A literature review by Cignacco et al. (2007) and a survey of hospitals in the United States on NICU infant stimulation (Field et al. 2006) identified multiple forms of common neonatal practices. Containment, music therapy, rocking (kinesthetic) and nonnutritive sucking were supportive techniques practiced by child life and nursing with infants in the NICU. Less frequently used infant stimulation practices indentified were the use of soft textures in bedding and infant massage. These findings are significant as they apply to present practice in NICU's. Other research reviewed in this paper highlights - the knowledge of the benefits of infant massage as a supportive strategy in increasing an infant's coping during painful procedures. The results of this survey shows that infant massage is practiced less frequently than expected, which suggests that it may not be readily adopted due to professional training and cost restraints (Field et al. 2006). Indeed formal training as a certified infant massage instructor (CIMI) must be completed in order to provide infant massage, and instruction to others - professional members of the medical team, parents/caregiver and volunteers (McGrath, Thillet, \& Van Cleave, 2007). Even with extensive benefits in parent-infant attachment, and increased parent and infant coping in the NICU, MCGrath, Thillet \& Van Cleave (2007) still appropriately caution nurses and members of the health care team to consider the risks and benefits for optimal implementation approaches of parent delivered infant massage becoming integrated as a common practice in the NICU. 


\section{Distraction Techniques:}

The use of toys as a method of distraction for young children's attention during painful procedures is studied in Landry \& Chapeiski's (1988) article on preterm infant visual attention. This article closely observes infant toy exploration, and compares the toy exploration attentional processes of high-risk, low-risk and no-risk infants, both with and without maternal involvement. Of the many findings of this study, the discovery of the high risk infant's attention to fewer toys as a potential adaptive behavior is important in influencing the type of toys used and determining the overall amount of distraction techniques that a child life specialist would use in working with a preterm infant during painful procedures. Another study, completed by Sinha et al. (2007) supports the use of distraction as a valuable Child Life technique in procedural pain management in pediatric emergency room care, which is not appropriate for pre-term infants. This study assessed pain and coping outcomes during painful procedures where a choice of distracters was offered to children 10 years of age or younger, to ensure that the activity was appealing to them. Important findings about younger patients were that music was the primary choice as a distracter, with videos, bubbles and books following as preferred choices (Sinha, et al. 2007). Based on these findings, music as a preferred distracter in young children when given a choice has implications for practice as an effective distraction technique in nonverbal infants undergoing painful procedures.

Infant pain and coping assessment tools and/or scales:

Many recent studies have been performed to evaluate the impact of nonpharmacological supportive techniques on infant stress and pain responses. In undertaking this literature review it was important for the author to consider as many tools as possible, and exclude those that do not meet the 
specific criteria for assessing infant coping during painful procedures, and for use by a CCLS. These studies use different behavioral and physiological assessment tools to observe, record and score patient responses to pain (Herr et al. 2006), or patient's adaptive coping efforts (Williamson, G., Zeitlin, \& Szczepanski, 1989). Literature regarding the use of assessment tools that require physiological measures (heart rate, oxygen saturation and vital signs) was extensively reviewed, including the Premature Infant Pain Profile (PIPP)(Bellini et al. 2006), the Neonatal Infant Pain Scale (NIPS)(Gallo, 2003), and the Neonatal Facial Image Scoring System (NFISS) (Chen, et al. 2005). Other valid and valuable tools were excluded from this study due to a CCLS inability to undertake the physiological part of the assessments individually, without assistance from a medical professional. Similarly valuable assessments that require any self-reporting, such as the Behavioral Approach-Avoidance and Distress Scale (BAADS) and the Faces Pain Scale were also excluded because the developmentally appropriate age for children who may be able to self report pain using a scale is 3 years of age, well above the focus $0-12$ month population this review of the literature focuses on (Kuttner, 2004; Herr et al. 2006). An additional excluded scale was the Brazelton Neonatal Behavioral Assessment Scale (NBAS) due to the fact that it detects behavioral differences in newborn infants of optimal health (Lundqvist \& Sabel, 2000), not the medically fragile population focused on in this literature review.

It is important to consider that no behavioral assessment scales have been determined to be better or more superior to others. However, selection of an appropriate scale should consider the tool that is most appropriate to the patient population being assessed and the types of pain and coping it has previously been tested on. Herr et al. (2006) and Van Dijk (2001) include thorough commentary, comparisons and evaluation of a number of infant assessment tools that do meet the search criteria. The clinical practice recommended assessments for use with nonverbal patient populations included in 
Herr et al. (2006) list 3 tools that fit the search criteria, and merit closer consideration. They were the COMFORT Behavior Scale, the Faces, Leg, Activity, Cry, Consolability Observational Tool (FLACC) and the Riley Infant Pain Scale (RIPS).

Van Dijk (2001) lists the RIPS characteristics for infant's 0-3years in acute care settings and in cases with surgical pain. The assessed characteristics include facial, cry, body movements, and additional items - sleep, consolability and response to touch. The FLACC has been tested in infants from 2 months to children up to 7 years of age. It has previously been tested for use in intensive and acute care populations, and with surgical and acute pain cases (Herr et al. 2006).

Although both tools met the search criteria, upon closer critical evaluation it is the author's opinion that these scales focus on pain response, not an infant's coping behaviors, that they do not meet the overall goal of the proposed project for improved infant coping following child life interventions. However, closer inspection of the COMFORT Behavior Scale demonstrates a better test population of 0-3years of age, and evidence based practice use in intensive care settings (Herr, et al. 2006). A revised scale of COMFORT measures constructs other than pain, but the age range increases to 0-9years of age. This scale observes 7 behaviors (alertness, calmness/agitation, respiratory response, crying, physical movement, muscle tone, facial tension) and includes a visual analogue scale (VAS) for the observer to indicate their personal visual assessment of the infant's pain at the moment.

One recent study proved the adapted COMFORT scale as a valid and reliable instrument to measure distress, pain and coping in premature infants with a gestational age between 28 to 37 weeks (Caljouw, et al. 2007). This research has determined that the revised version of the COMFORT Behavior Scale is the most appropriate for the goals of this research study. 
The final coping behavior assessment reviewed in the literature was the Early Coping Inventory (ECI) (Williamson, Zeitlin, \& Szczepanski, 1989). The ECl was designed to measure the presence or absence of coping behaviors in infants and toddlers in 3 categories of behavior (sensorimotor organization, reactive behavior, and self-initiated behavior) in which each of these categories includes items identified in research literature as highly relevant to coping. Williamson et al. (1989) studied the implications of this inventory in the assessment of disabled infants and toddlers ranging in age from 434 months of age and compared the results to non-disabled infants and toddlers. The findings were not surprising, the disabled infants and toddlers did not demonstrate effective coping behaviors compared to the non-disabled group in the study. The author does highlight the need for more research to enhance clinical practice and give practitioners a greater understanding of the specific variables that support effective coping in infants and young children. This $\mathrm{ECl}$ assessment is a valuable assessment tool for this study because it focuses on coping, and not pain response in young children. However, within the three categories of behavior measured there are some items that are not applicable to very young or premature infants, such as "attempting new behaviors independently" and "to alter behavior when necessary to solve a problem" (Williamson, et al. 1989, p. 7).

The field of Child Life continues to grow and improve upon evidence based nonmedical therapeutic services specifically prepared to meet the psychosocial coping needs of infants and young children in health care. The literature highlighted that some support techniques being provided to infants undergoing painful procedures were not provided by a CCLS. Many of those providing support included nurses and/or certified infant massage specialists. Research suggests that CCLS play an important role as part of interdisciplinary pain teams, and specifically focus on reducing young children's distress and facilitating coping during painful procedures. Premature and young infants have very few 
independent coping skills or behaviors and greatly benefit from Child Life procedural support and coping strategies. The research reviewed shows strong support and clear findings about the positive benefits of the implementation of supportive strategies for infants during painful procedures. However, studies also show that few CCLS feel skilled or adequately experienced in strategies beyond distraction and positions for comfort with infants, such as the complementary physical strategies of positive touch and infant massage. Further training opportunities are needed, along with the development of standard practice protocols for providing Child Life supportive strategies to infants during painful procedures as a means of improving infant coping. The successful completion of this pilot study hopes to influence future best practice standards for Child Life supportive care with infants and pre-term infants.

Earlier studies have focused on the measurement of infant pain during heel stick procedures to draw blood samples and the use of pain assessment tools to determine infant pain levels. Some studies have included the positive effects of positioning and infant massage on infants in pain that are not specifically provided by a CCLS. This pilot study focuses on supporting and increasing positive infant coping efforts through the provision of a range of Child Life support techniques (comfort positions, infant massage, and caregiver education/information) to improve infant care during painful procedures. The effectiveness of the Child Life supports provided in this pilot study hopes to demonstrate evidencebased methods that will inform the standards of best practice for Child Life support with infants. Evidence based practice methods integrate clinical experience and the highest quality available research to inform future Child Life practice (Koller, 2007).

The findings provided a strong theoretical basis for the use of a combination of support techniques with which to provide best practice Child Life support. This will be achieved through the use of comfort positions (including swaddling, prone, supine and side lying, infant massage (including gentle 
containment holds), and parent education and information (including infant development, explaining what happens during the ROP eye exam and how parents can be present and participate in supporting their infant during the examinations).

Theoretical framework:

The contextual perspective of Bronfenbrenner's (2005) bioecological theory provides an appropriate framework to guide the development of Child Life support protocols to improve infant coping during painful procedures. The bioecological theory describes the range of interacting influences that affect the developing child. This identifies a child's own biology as a critical environmental factor which affects development (Gardiner \& Kosmitzki, 2008). According to Bronfenbrenner, development occurs through regular, active two-way interactions between the child and the immediate environment. From this perspective an infant's distress, or lack of coping, is an outcome that is influenced by a number of factors, as shown in figure 1; the infants biological state, the social and physical environment and the infants ongoing process of psychological coping development (Ambuel, Hamlett, Marx, \& Blumer, 1992). This bi-directionality relates to the interaction between infant and CCLS during the provision of supportive interventions of the CCLS in developing and facilitating coping. Similarly, this bidirectionality also relates to the parent-infant relationship, as such the parent's inclusion in the child life support sessions is necessary when providing coping education and support. The use of this theoretical framework as a research strategy will examine the effectiveness of the integrated Child Life supportive interventions that will consider the infants existing coping strategies, the infant's biological state, the physical environment and the socially constructed environment (see Figure 2). 


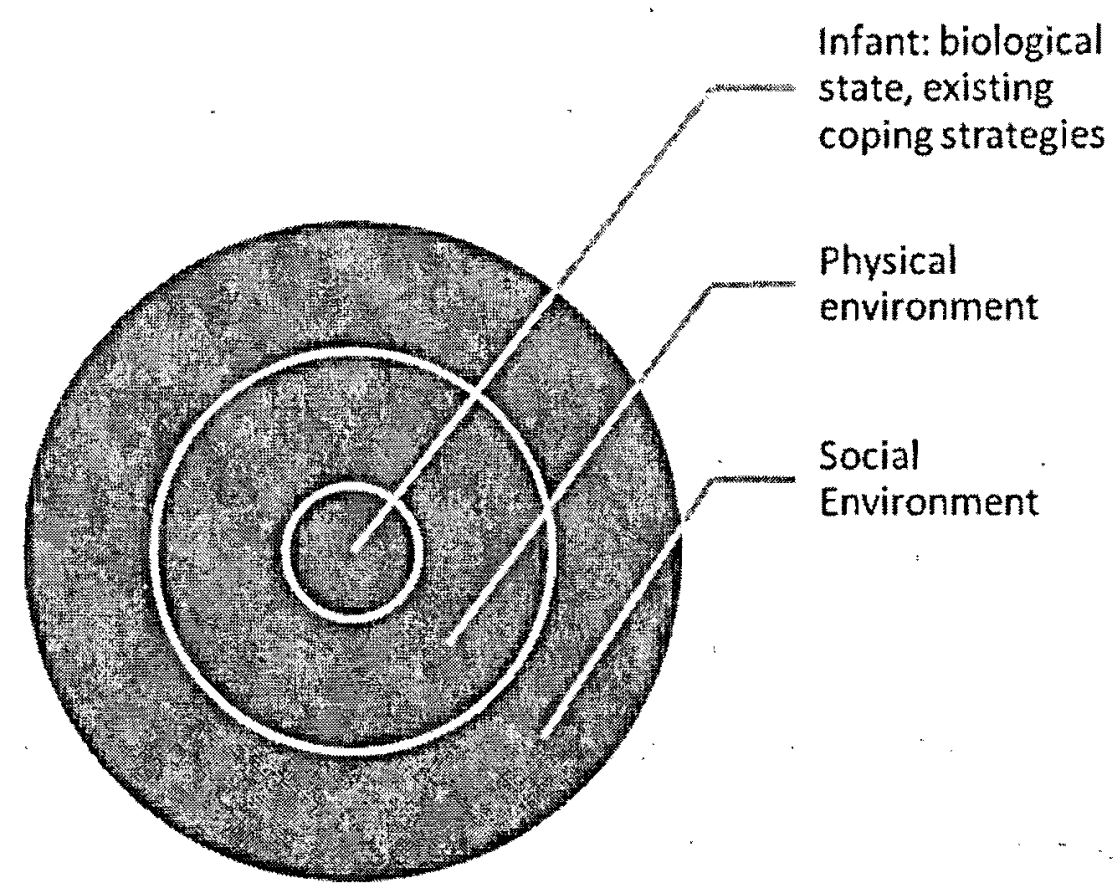

Figure 1: the present interaction

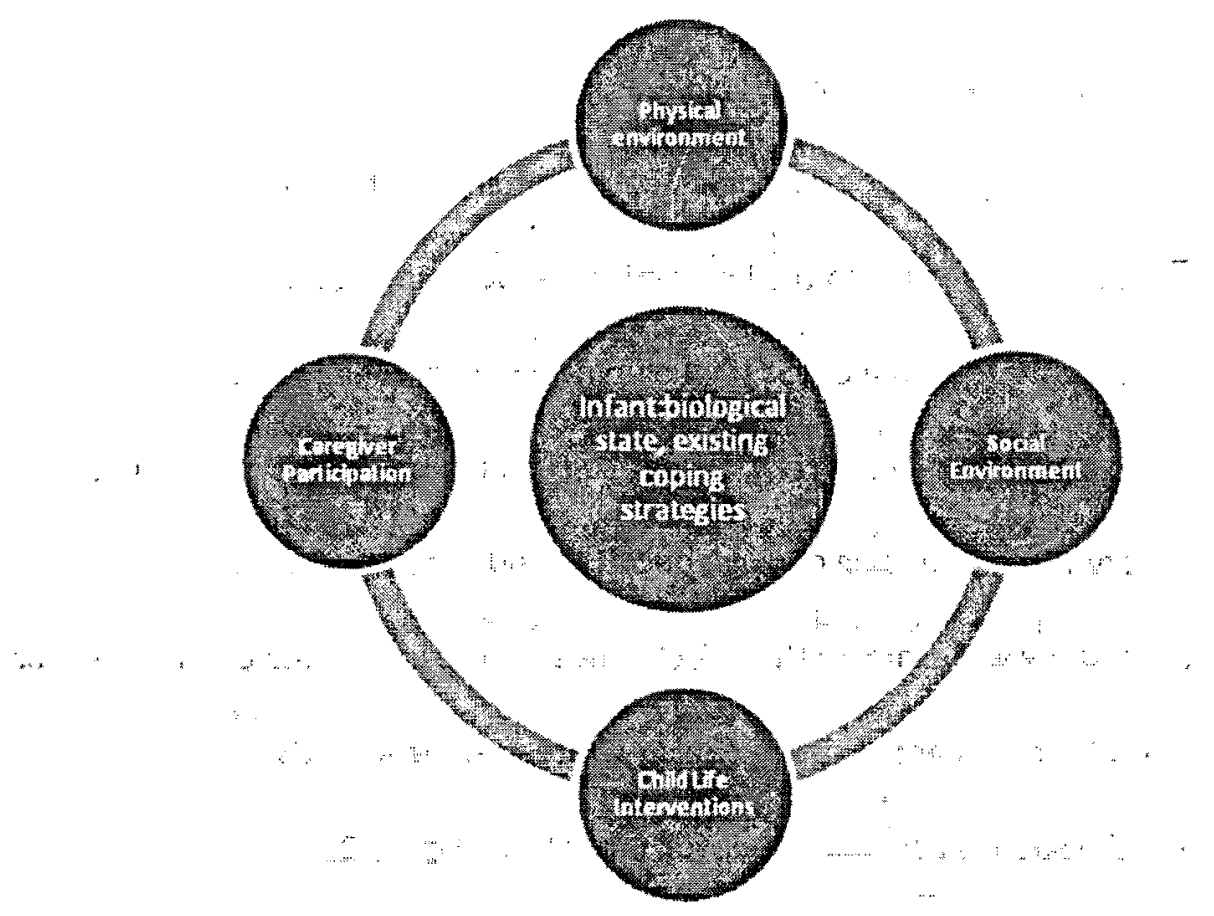

Figure 2: research study interaction 


\section{Chapter 3: Methodology}

Research Question:

Does the provision of Child Life supportive techniques to infants undergoing (painful) Retinopathy of Prematurity (ROP) eye exams improve/increase infant's procedural coping? Hypothesis:

The hypothesis of this study is that with the provision of 3 child life support sessions as a standard of practice a premature infant will demonstrate improved coping during painful ROP eye exams.

\section{Operational definitions:}

Child life supportive techniques/intervention - For this study the Child Life supportive techniques applied for increasing infant coping will include behavioral and physical strategies: infant massage strokes, comfort positions, containment holds and information/education for caregivers about the infant development, ROP eye exams and how they can best support their infant before, during and after the eye examinations.

Coping - is an active process of making adaptations to meet personal needs and to respond to the demands of the environment in order to maintain or enhance feelings of well being (Zeitlin, Williamson, \& Rosenblatt, 1987).

Corrected age - Premature babies (babies born before 37 completed weeks of pregnancy) are given two ages: chronological age and corrected age. Chronological age is a baby's age based on his or her birthday. Corrected age is based on the age the infant would be if he or she had been born on the : 
original due date. For example, if a baby should have been born on June 1st, his corrected age on September 1st will be 3 months old, even if he was born in April. Corrected age is not useful for a baby born only a few days or weeks early, because those babies are born near to full development.

Painful procedures - in this study the routine procedure involved includes: Retinopathy of Prematurity eye exams which entails the use of a speculum to hold the infants eyelids open while the ophthalmologist uses an instrument called a depressor to manipulate the eyeball for signs of disease. A bright light called an ophthalmoscope is also used to assist the doctor when checking the retina.

Scope:

This pilot study will focus on assessing infants coping while undergoing an ROP eye exam, before and after the provision of Child Life supportive techniques by a Certified Child Life Specialist who is dually certified as a massage instructor to determine if there is an improvement in infant coping following Child Life interventions.

This study will include a sample of up to 20 critical ROP infants that have been identified as needing a minimum of two ROP exams over a two to four week period of time in the Eye Clinic at Sick Kids Hospital in Toronto, Ontario, Canada.

Design:

This pilot research study will be mixed method including both quantitative and qualitative approaches, and will include a purposive sample of up to 20 outpatient ROP infants from birth up to 3 months of age corrected. The quantitative approach includes the use of the COMFORT scale as a validated, standardized assessment tool (see Appendix A). This standardized coping assessment tool to assess infant coping is used both before child life supportive interventions have been provided, and after 
child life supportive interventions have been provided. The qualitative approach includes the three hands on child life support sessions (Appendix B). The Child Life support sessions are qualitative as they include facilitated support interventions. Mixed-method is a way to develop creative alternatives to traditional or more monolithic ways to conceive and implement evaluation. This study is a genuine effort to be reflexive and more critical of the common standards within health care of evaluation practice and, ideally, will be more useful and accountable to broader audiences.

\section{Setting:}

This study will take place during the ROP clinic sessions in the Eye Clinic at Sick Kids Hospital in Toronto, Ontario. The Eye clinic covers a wide range of eye related care for children, but for this study the focus will be on the ROP eye exams taking place involving outpatient infants under 3 months of age.

Sampling Procedure:

A purposive consecutive sample of outpatient infants with retinopathy of prematurity or infants that are at risk for retinopathy of prematurity, less than 3 months of age will be selected and recruited during normal ROP clinic session days for this study. Clinical population size in the ROP eye clinic is approximately 500 new patients annually. Of this 500 , approximately 250 are considered critical. This sampling procedure will be undertaken by the patient coordinator in the eye clinic with no connection to the pilot study to avoid potential bias. The families will be asked if they are interested in learning about a study on infant coping, and will be asked if they would be willing to be contacted by phone by a researcher to explain the study in depth. The researcher will follow an approved telephone script that explains the study in greater detail (see Appendix C). After consent and the initial assessment of each 
infants coping during the first ROP eye exam, infants that do not meet the criteria of need for continued ROP examinations over a two to four week period will be excluded. This will allow for up to 20 infants to continue in the study.

Ambuel et al (1992) paper on the use of the COMFORT behavior scale reports a mean score of 20.2 $+/-5.3$. Based on this, we would need a sample size of 20 to detect a 5 point drop in comfort score and a sample size of 40 to detect a drop of 3.5 (reference: Lehr (1992) Sixteen S-squared over D-squared: a relation for crude sample size estimates. Statistics in Medicine, 11 (8): 1099-1102). We can justify this sample size based on our expected difference between baseline and post-intervention.

Ethical Issues:

The duration of the study took place over a short period of time, four weeks total length of time, which was necessary to reduce the normal maturational/developmental growth and change the infant will go through which could affect the coping results. Due to the critical and urgent nature of the ROP eye exam and the very short time in which infants are booked, examined and treated for ROP, there is a concern that parents will feel obligated or pressured to participate in this pilot study.

All concerns were addressed in the Research Ethics Board (REB) requirements to the parent in an information package study profile (Appendix D) and the consent form letter (Appendix E). The letter explains the voluntary nature of the study, their choice to say yes or no, drop out before completing, and that treatment is not dependent on participation. For participants that are English Language Learners (ELL) all efforts will be made to ensure written material is appropriately translated. Where ever possible, information given to caregivers during the child life support sessions will be physically demonstrated and shared through the use of Picture Image Cards (PICS). 
All patient numbers/files/data will be appropriately coded to ensure confidentiality. Subjects will be assigned a unique identification code and code breaking information will be kept separate from the date extraction files. This code breaking information will be kept inaccessible from anyone not participating as an investigator on this study.

Assessment and Intervention Timeline:

As mentioned in the previous section, time is an influencing factor in coping through natural infant growth and development. This is why the study took place over as short a period of time as possible. Some infant assessments took place within one week, and another infant's assessment took place over two weeks. The four week total length of time for this study is necessary, not to assess the infants over four weeks, which would be too long a period of time in which great growth and development would naturally take place, but because we needed four weeks in which to reach our goal of up to 20 infants for participation in the study. For example, one infant scheduled for an initial ROP exam may be considered critical, and would be scheduled for another ROP eye exam in one week time. Another infant may be booked for a follow up ROP eye exam two weeks following the initial assessment.

For detailed scripts of the child life support session interventions and timing, please see Appendix B.

Assessment Scale and Data Collection:

For this pilot study the COMFORT behavior scale (Appendix A) has been selected as a standardized tool to assess coping in infant patients during painful ROP eye exams, before and after receiving Child Life supports. This pilot study will use the English version of the standardized COMFORT behavior scale to assess each subject during a painful procedure (Ambuel et al, 1992). The COMFORT 
behavior scale was selected because it measures infant coping, not infant pain. Child Life supportive interventions are provided to help infants and children cope during painful procedures. This study is focused on the use of Child Life interventions to promote and facilitate coping in infants undergoing ROP eye exams.

The COMFORT behavior scale will be used for the observation of the infant's coping responses at the time of the eye exam procedure. This scale was selected because a CCLS cannot evaluate the biological or physiological status of any patients, as a non-medical member of the team. The initial assessment was completed at the initial ROP eye exam before the infant has received Child life coping support, and the final assessment was completed at the next scheduled ROP eye exam after the infant has received three Child Life coping support sessions. These sessions will include infant massage, positions for comfort and parent education/information. These three Child Life sessions were provided in the two to four weeks following the initial coping assessment.

The COMFORT behavior scale checklist provides a list of behaviors that are marked as either present (usually scored one to five) or absent (usually scored zero) and a Visual Analogue Scale (VAS), a ten centimeter long horizontal line with end points "no pain" and "worst pain". The VAS is a qualitative assessment, so in order to apply it as a quantitative measure for data analysis these points will be given a numeric value from one (no pain) to ten (worst pain) on which to rate the infants distress. While subjective and qualitative in nature, the ten-category scale will allow it to be applied as quantitative variable for data analysis. The comfort score is defined as the number of items checked. The VAS is scored out of ten (Nyren, 1988). The most common behavioral indices of infant coping during a painful procedure in this scale include vocal, verbal, facial, postural, and motor behaviors. No judgment of 
frequency of the behavior is made; each item is either absent or present. One advantage of this scale is speed and ease of use: the observers make a series of dichotomous judgments (Blauer \& Gerstmann, 1998).

The COMFORT behavior scale is recommended for pain and coping in children in critical care and for premature infants, as the planned sample will be, as it is the only well-studied instrument that makes explicit accommodation for constraints placed on the behavioral expression of pain by mechanical ventilation and physical restraint. The inter-rater reliability and internal consistency of this scale are strong. The physiological state of each infant cannot and will not be recorded during the assessment because the infants selected for this study are all outpatients.

Ethical Issues in Data Collection:

Building on past research conducted by Ambuel et al. (1992), this study will attempt to follow similar steps and procedures used to assess very young infant coping using the COMFORT behavior scale.

To assess observer agreement and inter-operator validity, each infant will be observed and scored by two raters simultaneously during the procedure. These observers will include an eye clinic fellow and an experienced ROP clinic nurse. Both observers will be trained to use the COMFORT behavior scale through an instructional CD ROM. The two observers will independently complete the COMFORT scale and Visual Analogue Scale (VAS) for each subject. The observers will observe the infant during the eye exam, which lasts between 2-5 minutes. Muscle tone will be assessed at the completion of the exam by gently flexing and extending the upper arm or thigh of the infant. The two observers would then complete the COMFORT scale independently. This should avoid the introduction of bias. 
Data Organization:

Data will be recorded manually on the standard COMFORT behavior scale checklist paperwork. Data will be kept in time order; utilizing a checklist for tasks to be achieved/are achieved. Timing could affect the collection of sufficient date, and/or reaching the ideal goal of up to 20 ROP infants.

Data Analysis and Interpretation:

The COMFORT behavior scale will be manually scored, and following each assessment the total score will be calculated, and any notes made with regards to the infants coping during the examination. Data will be entered into an excel spreadsheet and then transferred to a statistical analysis package (Statistical Package for the Social Sciences - SPSS). The COMFORT and VAS scales each have standardized measures of reliability and validity. Bivariate analysis using Pearson's R will assess the correlation or inter-rater agreement for the total COMFORT and VAS score, both before and after the experimental intervention. A t-test will be used to compare the mean value of the COMFORT and VAS scores before and after the intervention. 


\section{Chapter 4: Session Procedures:}

For study participants $1 \mathrm{c}$ and $1 \mathrm{i}$, the at home sessions were as follows.

The first home session with 1c started with the introduction of the infant massage materials, the oil, the instruction sheets and the blankets. Demonstrations of swaddling, comfort positions and the massage strokes went well, with the caregiver feeling confident in performing the strokes on the infant. The infants $(1 \mathrm{c})$ response was positive, with good eye contact with the caregiver maintained throughout the session, and by the end of the session the infant was so relaxed he fell asleep. The caregiver and CCLS discussed different positions and adaptations of infant massage strokes for premature infants with multiple medical needs. There were no caregiver questions at this time about the ROP exam procedures.

The second session revisited the past strokes before introducing the next series of strokes. The caregiver reported performing massage routine with the infant on a daily basis since the first session. The infant (1c) clearly recognized the massage preparation and focused on eye contact with his caregiver and relaxed his overall muscle tension before the massage demonstration began. When undertaking the massage strokes, the CCLS demonstrated the adaptations necessary to perform the strokes around infant $1 c^{\prime}$ s large protruding hernia. The caregiver was comfortable with these adaptations and performed the strokes with confidence. Infant 1c showed no discomfort or distress with strokes and fell asleep again at the end of the child life session.

The third session revisited the last strokes, clarified the ROP eye exam and the risks of ROP, and discussed the upcoming eye exam and post test assessment that would be taking place at Sick Kids. The final massage strokes were demonstrated by the CCLS and the caregiver performed each stroke with confidence on the infant. Infant $1 \mathrm{c}$ responded positively to the strokes staying awake and alert 
throughout the session.

The first home session for Infant $1 i$ included the participation of both caregivers and the infant 1i's twin. Both caregivers expressed a desire to learn the coping support techniques, therefore it was determined that the twin could be included and participate in all 3 Child Life sessions despite their not being at risk for ROP. This first session began with introducing the materials and preparing the infants for positioning and massage. The CCLS demonstrated each of the possible positions for comfort and massage and the caregivers selected their preferred position before starting the massage strokes. $1 \mathrm{i}$ and her twin responded to the strokes, and were fully relaxed and asleep before the end of the massage demonstrations. The CCLS continued the demonstration of the final few strokes to ensure the caregivers received instruction on all the strokes for the first session, despite their lack of ability in practicing these strokes on the sleeping infants. During the questions segment of the session, both caregivers requested more information about ROP, the examination, and what the ophthalmologist was looking for as a sign of the disease in the infants. The CCLS answered their questions and provided a diagram of the progression of ROP eye disease for better comprehension and understanding.

The second session took place after $1 \mathrm{i}$ and her twin had finished a feeding. Both infants needed to be burped before the child life session could begin. The CCLS shifted the question part of the session to the beginning along with the stroke review while awaiting both infants readiness. The CCLS discussed the importance of adjusting the pressure of infant massage strokes to the preference of the infant. $1 \mathrm{i}$ was ready to proceed with the massage portion of session 2 , but her twin was unable to participate as she had fallen asleep. One of the caregivers used a demonstration doll for practicing the strokes so as not to disturb the sleeping infant. 
Session three was a successful and engaging session as both $1 \mathrm{i}$ and her twin were awake and alert for the session. The parents displayed greater confidence in performing the positions and strokes and expressed enjoyment about introducing this into the daily routine. The CCLS went over the upcoming follow up post test eye exam at Sick Kids, clarifying location and time of the exam. Due to recent issues with constipation in infant $1 i$, the CCLS revisited the tummy strokes to aid bowel movements and assist in expelling gas. 
Chapter 5: Results:

Despite vigorous recruitment and review of all outpatient infants attending the ROP clinic at Sick Kids Hospital over the 4 week time period, only 9 infants were consented into the study, and of those 9 infants only 2 were found to be at risk for ROP, with visible signs of disease in both eyes.

Table 1 displays the COMFORT behavior scale scores assessed by the ROP nurse for the 9 consented infants at their initial ROP eye exam.

Table 1. Initial assessment infant scores by ROP nurse

\begin{tabular}{|c|c|c|c|c|c|c|c|c|c|c|}
\hline subie & Alert & $\begin{array}{l}\text { Colmness age } \\
\text { tation }\end{array}$ & cry & $\begin{array}{l}\text { Prysical in } \\
\text { movement }\end{array}$ & $\begin{array}{l}\text { Musters } \\
\text { tore }\end{array}$ & $\begin{array}{l}\text { Tacial } \\
\text { tension }\end{array}$ & 15: & Tot & Medicat: & cilis rondivon \\
\hline $1 \mathrm{~A}$ & 4 & 3 & 4 & 2 & 1 & 1 & 3 & 18 & sucrose & pacifier \\
\hline $1 \mathrm{~B}$ & 4 & 4 & 4 & 4 & 3 & 3 & 3 & 25 & sucrose & pacifier \\
\hline $1 C$ & 4 & 3 & 2 & 3 & 3 & 4 & 3 & 22 & sucrose & pacifier, 02 , constipated \\
\hline 1D & 4 & 3 & 4 & 3 & 3 & 2 & 2 & 21 & sucrose & no pacifier \\
\hline $1 E$ & 4 & 3 & 4 & 4 & 3 & 3 & 3 & 24 & sucrose & pacifier \\
\hline $1 F$ & 4 & 3 & 4 & 3 & 3 & 2 & 2 & 21 & sucrose & pacifier, constipated \\
\hline $1 \mathrm{G}$ & 4 & 4 & 5 & 4 & 4 & 3 & 2 & 26 & sucrose & pacifier \\
\hline $1 \mathrm{H}$ & 4 & 3 & 4 & 3 & 4 & 3 & 4 & 25 & sucrose & pacifier, mothers voice \\
\hline 11 & 4 & 3 & 3 & 2 & 4 & 3 & 2 & 21 & sucrose & $\begin{array}{l}\text { pacifier, fed } 1 \mathrm{hr} \text { prior, more } \\
\text { agitated } 2 \text { nd eye }\end{array}$ \\
\hline
\end{tabular}

Table 2 displays the Comfort behavior scale scores assessed by the clinic fellows for the 9 consented infants at their initial ROP eye exam. 
Table 2. Initial assessment infant scores by clinic fellows

\begin{tabular}{|c|c|c|c|c|c|c|c|c|c|c|}
\hline subse & $\begin{array}{l}\text { Alert } \\
\text { ness }\end{array}$ & $\begin{array}{l}\text { Camnestag } \\
\text { tation. }\end{array}$ & cryi: & $\begin{array}{l}\text { Physical } \\
\text { movement }\end{array}$ & $\begin{array}{l}\text { Muscte } \\
\text { tone }\end{array}$ & $\begin{array}{l}\text { Facuifin } \\
\text { terision. }\end{array}$ & AS. & $\begin{array}{l}\text { Fot } \\
\text { al }\end{array}$ & $\begin{array}{l}\text { Medicat } \\
\text { ions }\end{array}$ & Chiles condtion \\
\hline $1 \mathrm{~A}$ & 1 & 3 & 4 & 3 & 3 & 3 & 4 & 18 & sucrose & pacifier \\
\hline 18 & 4 & 3 & 4 & 3 & 4 & 3 & 3 & 25 & sucrose & pacifier \\
\hline $1 C$ & 4 & 2 & 3 & 4 & 4 & 4 & 7 & 22 & sucrose & pacifier, 02 , constipated \\
\hline 10 & 4 & 4 & 5 & 4 & 4 & 5 & 8 & 21 & sucrose & no pacifier \\
\hline $1 \mathrm{E}$ & 2 & 3 & 4 & 3 & 4 & 3 & 3 & 24 & sucrose & pacifier \\
\hline 1F & 3 & 2 & 2 & 3 & 3 & 2 & 2 & 21 & sucrose & pacifier, constipated \\
\hline $1 G$ & 4 & 4 & 4 & 4 & 4 & 3 & 3 & 26 & sucrose & pacifier \\
\hline $1 \mathrm{H}$ & 4 & 3 & 3 & $: 3$ & 4 & 4 & 4 & 25 & sucrose & pacifier, mothers voice \\
\hline 11 & 2 & 2 & 2 & 3 & 4 & 3 & 3 & 21 & sucrose & $\begin{array}{l}\text { pacifier, fed } 1 \mathrm{hr} \text { prior, more } \\
\text { agitated } 2 \text { nd eye }\end{array}$ \\
\hline
\end{tabular}

When comparing these initial assessment scores between raters, ROP nurse and fellows, there is no statistical difference between the pre scores, proving the validity and reliability of the COMFORT behavior scale, even without extensive training. The significant statistical associations highlighted by the pre test correlation of the variables between raters is indicated in Table 3 by ${ }^{*}$, or ** are physical movement, muscle tone, facial tension, VAS and the total COMFORT behavior scale scores. These correlations show strong relations between variables even with this small sample. Alertness by itself has no significant correlations. 
Table 3. Pre-test Measures only Correlations

\begin{tabular}{|c|c|c|c|c|c|c|c|c|c|}
\hline & & VAS & Alertness & Calmness/agitation & Crying & $\begin{array}{l}\text { Physical } \\
\text { movement }\end{array}$ & $\begin{array}{c}\text { Muscle } \\
\text { tone }\end{array}$ & $\begin{array}{l}\text { Facial } \\
\text { tension }\end{array}$ & Total \\
\hline VAS & $\begin{array}{l}\text { Pearson } \\
\text { Correlation } \\
\text { Sig. (2- } \\
\text { tailed) }\end{array}$ & 1 & $\begin{array}{r}.043 \\
-.866\end{array}$ & $\begin{array}{r}.034 \\
.893\end{array}$ & $\begin{array}{r}.184 \\
.466\end{array}$ & $\begin{array}{l}.410 \\
.091\end{array}$ & $\begin{array}{l}.268 \\
.283\end{array}$ & $\begin{array}{r}.707(* *) \\
.001\end{array}$ & $\begin{array}{r}.750\left(^{* *}\right) \\
.000\end{array}$ \\
\hline $\begin{array}{c}\text { Alertness } \\
\text {.. }\end{array}$ & $\begin{array}{l}\text { Pearson } \\
\text { Correlation } \\
\text { Sig. (2- } \\
\text { tailed) }\end{array}$ & & 1 & $\begin{array}{l}.344 \\
.162\end{array}$ & $\begin{array}{l}.201 \\
.423\end{array}$ & $\begin{array}{l}.175 \\
.486\end{array}$ & $\begin{array}{r}. .036 \\
.887\end{array}$ & $\begin{array}{l}.070 \\
.782\end{array}$ & $\begin{array}{l}.387 \\
.113\end{array}$ \\
\hline Calmness/agitation & $\begin{array}{l}\text { Pearson } \\
\text { Correlation } \\
\text { Sig. (2- } \\
\text { tailed) }\end{array}$ & & & 1 & $\begin{array}{r}.742\left(^{* *}\right) \\
.000\end{array}$ & $\begin{array}{r}.395 \\
.104\end{array}$ & $\begin{array}{l}.065 \\
.797\end{array}$ & $\begin{array}{l}.203 \\
.420\end{array}$ & $\begin{array}{r}.546\left(^{*}\right) \\
.019\end{array}$ \\
\hline Crying & $\begin{array}{l}\text { Pearson } \\
\text { Correlation } \\
\text { Sig. (2- } \\
\text { tailed) }\end{array}$ & & $\therefore$ & $\therefore$ & . & $\begin{array}{l}.353 \\
.151\end{array}$ & $\begin{array}{r}.009 \\
\because .971\end{array}$ & $\begin{array}{r}.000 \\
1.000\end{array}$ & $\begin{array}{r}.529(") \\
. \quad .024\end{array}$ \\
\hline $\begin{array}{l}\text { Physical } \\
\text { movement }\end{array}$ & $\begin{array}{l}\text { Pearson } \\
\text { Correlation } \\
\text { Sig. (2- } \\
\text { tailed) }\end{array}$ & & & $\cdots$ & & 1 & $\begin{array}{r}.374 \\
.126\end{array}$ & $\begin{array}{r}.501\left(^{*}\right) \\
.034\end{array}$ & $\begin{array}{r}.703\left({ }^{\star \star}\right) \\
.001\end{array}$ \\
\hline . & $\begin{array}{l}\text { Pearson } \\
\text { Correlation } \\
\text { Sig. (2- } \\
\text { tailed) }\end{array}$ & & . & . & . & - & 1 & $\begin{array}{r}.662\left(^{* *}\right) \\
.003\end{array}$ & $\begin{array}{r}.522\left(^{*}\right) \\
.026\end{array}$ \\
\hline Facial tension & $\begin{array}{l}\text { Pearson } \\
\text { Correlation } \\
\text { Sig. (2- } \\
\text { tailed) }\end{array}$ & & $m=$ & $\because n$ & & & & $\begin{array}{r}1 \\
-.3\end{array}$ & $\begin{array}{r}.778\left(^{* \star}\right) \\
.000\end{array}$ \\
\hline Total & $\begin{array}{l}\text { Pearson } \\
\text { Correlation } \\
\text { Sig. (2- } \\
\text { tailed) }\end{array}$ & & & & & & & & 1 \\
\hline
\end{tabular}

** Correlation is significant at the 0.01 level (2-tailed).

- Correlation is significant at the 0.05 level (2-tailed).

$N=18$

The post test results with the 2 study participants, $1 \mathrm{c}$ and $1 \mathrm{i}$, show a noticeable drop in most 
individual variables, and the total scores on the COMFORT behavior scale, indicating better, more effective coping in the infants undergoing their follow up eye exam. Table 4 includes all pre and post test scores for both the nurse and fellow for comparison and ease of readability.

Table 4. Nurse and Fellow pre and post test scores for study infants $1 \mathrm{c}$ and $1 i$.

Nurse pretest infant $1 \mathrm{c}$

\begin{tabular}{|ll|}
\hline ITEM & SCORE \\
Alertness & 4 \\
Calmness/Agitation & 3 \\
Crying & 2 \\
Physical Movement & 3 \\
Muscle Tone & 3 \\
Facial Tension & 4 \\
VAS & 3 \\
Total (out of 40) & 22 \\
\hline
\end{tabular}


Fellow pretest infant $1 \mathrm{c}$

\begin{tabular}{|ll|}
\hline ITEM & SCORE \\
Alertness & 4 \\
Calmness/Agitation & 2 \\
Crying & 2 \\
Physical Movement & 4 \\
Muscle Tone & 4 \\
Facial Tension & 4 \\
VAS & 7 \\
Total (out of 40) & 27 \\
\hline
\end{tabular}

Fellow post test infant $1 \mathrm{c}$

\begin{tabular}{|ll|}
\hline ITEM & SCORE \\
Alertness & 4 \\
Calmness/Agitation & 2 \\
Crying & 2 \\
Physical Movement & 2 \\
Muscle Tone & 2 \\
Facial Tension & 2 \\
VAS & 2 \\
Total (out of 40) & 16 \\
\hline
\end{tabular}


Nurse pretest infant $1 i$

\begin{tabular}{|ll|}
\hline ITEM SCORE & Slertness \\
Calmness/Agitation & 3 \\
Crying & 3 \\
Physical Movement & 2 \\
Muscle Tone & 4 \\
Facial Tension & 3 \\
VAS & 2 \\
Total (out of 40) & 21 \\
\hline
\end{tabular}

Nurse post test infant $\mathbf{1 i}$

\begin{tabular}{|ll|}
\hline ITEM & SCORE \\
Alertness & 3 \\
Calmness/Agitation & 2 \\
Crying & 2 \\
Physical Movement & 2 \\
Muscle Tone & 2 \\
Facial Tension & 2 \\
VAS & 2 \\
Total (out of 40) & 15 \\
\hline
\end{tabular}


Fellow pretest infant $1 i$

\begin{tabular}{|ll|}
\hline ITEM & SCORE \\
Alertness & 2 \\
Calmness/Agitation & 2 \\
Crying & 2 \\
Physical Movement & 3 \\
Muscle Tone & 4 \\
Facial Tension & 3 \\
VAS & 3 \\
Total (out of 40) & 19 \\
\hline
\end{tabular}

Fellow post test infant 11

\begin{tabular}{|ll|}
\hline ITEM & SCORE \\
Alertness & 3 \\
Calmness/Agitation & 2 \\
Crying & 2 \\
Physical Movement & 2 \\
Muscle Tone & 2 \\
Facial Tension & 2 \\
VAS & 1 \\
Total (out of 40) & 14 \\
\hline
\end{tabular}




\section{Chapter 6: Discussion:}

Preliminary findings indicate that the development and implementation of child life support sessions for ROP infants and caregivers does demonstrate an increase in infant coping during ROP eye exams. Due to the small sample participation in this study, the findings suggest a full study is necessary and appropriate to investigate these benefits on a larger scale and over a longer period of time. In conducting this observational pilot study, we were guided by a pre-determined and pre-researched set of variables in the COMFORT behavior scale expressed as Likert scales from a previously tested instrument. The pre and post scores are objective measures of a subjective observer assessment. In comparing the ROP nurses assessment scores and the scores of the clinic fellows, the fact that there is no statistical difference in the scores proves the validity and reliability of the behavior scale even with minimal or no training.

Looking closely at the statistically significant results in the between raters pretest infant coping scores for specific measures, it is clear that the associations demonstrate strong relations between variables even with this small sample size. The VAS total score correlation of .750 is significant at the 0.01 level (2-tailed). The calmness/agitation total score correlation of .546 is significant at the 0.05 level (2-tailed). The crying total score correlation of .529 is significant at the 0.05 level (2-tailed). The physical movement total score correlation of .703 is significant at the 0.01 level (2-tailed). The muscle tone total score correlation of .522 is significant at the 0.05 level (2-tailed). The facial tension total score correlation of .778 is significant at the 0.01 level (2-tailed).

The pre to post test scores for both infant $1 \mathrm{c}$ and infant $1 \mathrm{i}$ showed a drop, indicating increased coping and decreased distress. The specific measures with the more noticeable drop in scores were 
physical movement, muscle tone, facial tension and the VAS. The overall drop in the nurse pre/post test total score for infant $1 \mathrm{c}$ was 7 points. The overall drop in the fellow pre/post test total score for infant $1 \mathrm{c}$ was 11 points. The overall drop in the nurse pre/post test total score for infant $1 i$ was 6 points. The overall drop in the fellow pre/post test total score for infant $1 \mathrm{i}$ was 5 . These results illustrate and prove that even minimal child life support sessions, three 30 minute home sessions, were sufficient to produce a noticeable increase in infant coping scores and a decrease in distress.

The study findings did indicate that the variable Alertness did not have any significant correlations and could effectively be removed from the assessment. This challenges the constructions of the test instrument, and the application of this variable in an ROP eye exam. The alertness results may be because all infants were scored high in alertness. This could be due to physical/environmental factors in the hospital environment: the time of day the appointment was scheduled, the artificial lighting, the clinic environment, the preceding eye drops used to dilate the pupils or it could be some as of yet unknown variable. This could also affect the outcomes of this study.

When analyzing the crying scores, it was clear that the scores remain steady/static across both the pre and post test assessments. This supports the child life belief that crying is in itself a valuable coping mechanism for infants and children in pain or under stressful circumstances (Bandstra et al. 2008).

The small sample size limitation allowed us a snapshot of trends in infant coping during ROP eye exams, which suggests a full study is necessary and appropriate to demonstrate more significant statistical significance.

The use of Bronfenbrenner's bioecological theory highlighted the multiple interacting influences 
affecting the infants coping development. Through the introduction of the CCLS support sessions the interacting influences were positively changed in order to achieve a positive increase in development of the infants coping, thus fulfilling the study hypothesis. The study directly and indirectly effected the infant's bi-directional interaction with each of the physical and social environmental factors: parentinfant, CCLS-infant, fellow-infant, ophthalmologist-infant, social-environment-infant, and the physical environment-infant. These parameters were affected and influenced just by the mere inclusion of the infant in the study.

Limitations:

The primary limitation to the pilot study was the small sample size. Subject recruitment was a complex process during which a number of factors related to the highly complex nature of the outpatient population were considered. Many of the consented infants were found to not be at risk for ROP and therefore could not participate and continue in the study after their initial assessment. A possible reason for the majority of the babies to be not at risk for ROP could be because as premature babies grow and develop up to their actual term birth date, many of them through natural growth and development develop out of risk. Simply put, as a premature baby grows, as they would in the womb, their eyes should grow and develop to the normal point they would at full term birth which places them not at risk for ROP. There are similar intake issues documented in recent research studies with this population. In a study undertaken by Livingstone, Beider, Kany, Gallardo, Joseph \& Gold (2007) investigating the efficacy of the development and implementation of an infant massage program for medically fragile infants, only 12 infants were recruited over a 12 month period; 7 in the control group and 5 in the experimental group. 
Performing this study in the summer meant that a number of clinic staff were away on vacation. This meant that there was inconsistent staff involvement in the doctors performing the eye exams, the fellows participating in the coping assessments, and inconsistencies in the nurses providing containment holds during the eye exam. Other noted impacts due to staff holidays were longer wait times and delays due to overbooked clinics because of inadequate coverage for vacationing staff. The only study constants were the intake coordinator remained the only hospital staff member contacting and inviting families to participate, and the experienced ROP nurse participating in the study that discussed the consenting process with caregivers and witnessed all the signing of consent forms. This same experienced ROP nurse was also the consistent rater of each infants coping assessment.

When looking at the infant scores it is obvious that the nurse and fellow did not score many infants at a 1 or a 5 . This is a common trend found in scaled assessments; not selecting the highest or lowest scores (Locke, Silverman, \& Spiriduso, 2004). This is shaped by training and ideologies in the clinic, including the myth that most babies do not experience pain - a long standing belief that is slow to change despite the evidence (VanDijk, et al. 2001). This is an illustration of subjectivity and rater bias which is inherent whenever using a rater scale. The pre and post scores are objective measures of a subjective observer assessment.

Recommendations/Future Research:

Further research should be completed, replicating this study on a larger scale, using a control group and taking place over a longer period of time in order to influence and positively change the standards of best practice of coping support provided to infants and children in health care. A larger study with a bigger sample will allow for greater analysis and comparison of the infant's assessment 
scores between and within raters, increasing the statistical significance necessary to impact and influence change in the pediatric medical field. Adding an additional rater to bring the number of total raters to three, would also allow for increased analysis and comparison between and within raters. However, this small study does suggest that through the provision of child life support sessions one can increase and enhance the procedural coping in premature infants during painful routine procedures. Implementing the strategies used in this small pilot study will positively benefit infants coping when undergoing painful procedures.

It is evident from the results that some investigation into crying as a valid and valuable coping mechanism should look to determine the different variables and influencing factors in its use in infants and children's existing coping strategies. From this investigation, further research through studies into the use of crying as a coping tool could impact and change ideologies long held in the field of child development and pediatric medicine about crying as a negative behavior.

Further research as a whole needs to be undertaken by CCLS's with regards to enhancing the procedural supports presently being provided in pediatric healthcare to include more supports for infants and children coping with illness, medical/surgical needs and trauma.

Conclusion:

This study demonstrated the feasibility and benefit of child life support sessions in increasing and improving coping in premature infants during ROP eye exams. Our findings indicate that a properly designed and implemented child life support program performed by specially trained child life specialists can be safely practiced with premature babies and their caregivers in their homes. Continued research needs to be completed on a larger sample, using a control group, with at least three raters observing 
and scoring infant coping, and taking place over a longer period of time. Influencing the standards of best practice in coping support for infant and children in the field of pediatric medicine can be achieved with a larger study comparing greater statistical results. 


\section{References:}

Ambuel, B., Hamlett, K.W., Marx, C.M., \& Blumer, J.L. (1992). Assessing distress in pediatric intensive care environments: the COMFORT scale. Journal of Pediatric Psychology, 17 (1), 95-109.

American Academy of Pediatrics. (2000). Child life services. Pediatrics. 106(5), 1156-1159.

Andrews, G., Tennant, C., Hewson, D., and Vaillant, G.( 1978). Life event stress, social support, coping styles and risk of psychological impairment. Journal of Nervous and Mental Disease 166, 307316.

Bachanas, P.J., \& Blount, R.L. (1996). The behavioral approach-avoidance and distress scale: and investigation of reliability and validity during painful procedures. Journal of Pediatric Psychology. 21(5), 671-681.

Bandstra, N.F.,Skinner, L., LeBlanc, C., Chambers, C. T., Hollon, E. C. Brennan, D. \& Beaver, C. (2008). The role of child life in pediatric pain management: a survey of child life specialists. The Journal of Pain. 1-10.

Bellieni, C.V., Cordelli, D.M., Caliani, C., Palazzi, C., Franci, N., Perrone, S., Bagnoli, F. \& Buonocore, G. (2007). Inter-observer reliability of two pain scales for newborns. Early Human Development. 83, 549-552.

Berkow, R. \& Fletcher, A.J. (Eds.).(1987). The Merck Manual of Diagnosis and Therapy. New Jersey: Merck Sharp \& Dohme Research Laboratories.

Blauer, T. \& Gerstmann, D. (1998). A simultaneous comparison of three neonatal pain scales during common NICU procedures. The Clinical Journal of Pain. 14 (1), 39-47.

Blount, R.L., Piira, T., Cohen, L.L, \& Cheng, P.S. (2006). Pediatric procedural pain. Behavior Modification. 30(1), 24-49.

Bronfenbrenner, Urie. (2005). Making human beings human: Bioecological perspectives on human development. Thousand Oaks, CA: Sage Publications.

Caljouw, M.A., Kloos, M.A., Olivier, M.Y., Heemskerk, I.W., Pison, W.C, Stiger, G.D., \& Verhoef, AM, J. (2007). Measurement of pain in premature infants with a gestational age between 28 to 37 weeks: validation of the adapted COMFORT scale. Journal of Neonatal Nursing. 13, 13-18.

Canadian Retinoblastoma Society. http://www.rbsociety.ca/home.html

Chen, K.H., Chang, S., Hsaio, T.C., Chen, Y.C. \& Lin, C.W. (2005). A neonatal facial image scoring system (NFISS) for pain response studies. Biomedical Engineering-Applications, Basis \& Communications. 17, 19-26.

Child Life Council. (2002). Official Documents of the Child Life Council. Rockville, Maryland: Child Life Council Inc. 
Child Life Council Committee on Hospital Care. (2006). Policy statement: child life services. Pediatrics. 118(4), 1757-1763.

Child Life Council. (2008). Child Life Services Fact Sheet. Rockville, Maryland: Child Life Council Inc.

Cignacco, E., Hamers, J.P., Stoffel, L., VanLingen, R.A., Gessler, P., McDougall, J. \& Nelle, M. (2007). The efficacy of non-pharmacological interventions in the management of pain in preterm and term neonates: a systematic literature review. European Journal of Pain. 11, 139-152.

Elliott, C.H., Jay, S.M. \& Woody, P. (1987). An observation scale for measuring children's distress during medical procedures. Journal of Pediatric Psychology. 12(4), 543-551.

Field, T., Diego, M. \& Hernandez-Reif, M. (2007). Massage therapy research. Developmental Review. 27, 75-89.

Field, T., Hernandez-Reif, M., Feijo, L. \& Freedman, J. (2006). Prenatal, perinatal and neonatal stimulation: a survey of neonatal nurseries. Infant Behavior \& Development. 29, 24-31.

Field, T. (1986). Interventions for premature infants. Journal of Pediatrics. July, 183-191.

Gallo, A.M. (2003). The fifth vital sign: implementation of the neonatal infant pain scale. JOGNN. 32(2), 199-206.

Gardiner, H.W. \& Kosmitzki, C. (2008). Lives across cultures: Cross-cultural human development $\left(4^{\text {th }}\right.$ ed.). Boston: Pearson Education.

Gibbins, S. (2007). Pain management: what is the right outcome? Newborn and Infant Nursing Reviews. $7(1), 47-48$.

Harrison, L.L. (2001). The use of comforting touch and massage to reduce stress for preterm infants in the neonatal intensive care unit. Newborn and Infant Nursing Reviews. 1(4), 235-241.

Hernandez-Reif, M., Diego, M. \& Field, T. (2007). Preterm infants show reduced stress behaviors and activity after 5 days of infant massage therapy. Infant Behavior \& Development.30, 557-561.

Herr, K., Coyne, P.J. Key, T., Manworren, R., McCaffrey, M., Merkle, S., Pelosi-Kelly, J., \& Wild, L. (2006). Pain assessment in the nonverbal patient: position statement with clinical practice recommendations. $7(2), 44-52$.

Hicks, M., \& Lavender, R. (2001). Psychosocial practice trends in pediatric oncology. Journal of Pediatric Oncology Nursing. 18 (4), 143-153.

Jordan-Marsh, M., Hubbard, J., Watson, R., Hall, R.D., Miler, P., \& Mohan, O. (2004). The social ecology of changing pain management: do I have to cry? Journal of Pediatric Nursing. 19(3), 193-203.

Kleinberg, S. (1987). Child life in the 1990's: changing roles, changing times. Children's Health Care. 15(4), 240-244. 
Koller, D. (2007). Preparing children and adolescents for medical procedures. Child Life Council Evidence Based Practice Statement. 1-13. From http://www.childlife.org

Kuhn, C.M., Schanberg, S.M., Field, T., Symanski, R., Zimmerman, E., Scafidi, F. \& Roberts, J. (1991). Tactile-kinesthetic stimulation effects on sympathetic and adrenocortical function in preterm infants. Journal of Pediatrics. 119(3), 434-440.

Kuttner, L. (2004). A child in pain: how to help, what to do. Hartley \& Marks: Canada.

Landry, S.H. \& Chapieski, M.L., (1988). Visual attention during toy exploration in preterm infants: effects of medical risk and maternal interactions. Infant Behavior and Development. 11, 187-204.

Livingstone, K., Beider, S., Kany, A.J., Gallardo, C.C., Joseph, M.H. \& Gold, J.I. (2007). Touch and massage for medically fragile infants. Oxford Journals eCAM Advance Access. August 6, 2007, 1-10.

Locke, L.F., Silverman, S.J., \& Spiriduso, W.W. (2004). Reading and Understanding Research. London: Sage.

Lundqvist, C., \& Sabel, K.G. (2000). Brief report: the Brazelton neonatal behavioral assessment scale detects differences among newborn infants of optimal health. Journal of Pediatric Psychology. 25(8), 577-582.

McClure, V. (2000). Infant massage: A handbook for loving parents. ( $3^{\text {rd }}$ ed.). New York: Bantam Books.

McGee, K. (2006). The role of child life specialists in pediatric radiology department. Pediatric Radiology. 33 (7), 467-474.

McGrath, J. M., Thillet, M., \& Van Cleave, L. (2007). Parent delivered infant massage: are we truly ready for implementation? Newborn and Infant Nursing Reviews. 7(1), 39-46.

Mitchell, A., \& Brooks, S. (2000). The premature infant and painful procedures. Pain Management Nursing. 1(2), 58-65.

Mitchell, A., \& Waltman, P.A. (2003). Oral sucrose and pain relief for preterm infants. Pain Management Nursing. 4(2), 62-69.

Morris, L.W. and Engle, W.B.(1981).Assessing various coping strategies and their effects on test performance. Journal of Clinical Psychology 37,165-171.

Noll, R.B. \& Kulkarni, R. (1989). Cognitive and motor development of infants coping with cancer: longitudinal observations. Infant Mental Health Journal. 10 (4), 252-262.

Nyren, O. (1988). Visual analogue scale. In M. Hersen \& A.S. Bellack, (Eds.), Dictionary of behavioral assessment techniques. (pp. 490-491). New York: Pergamon.

Pearlin, L.I. and Schooner, C. (1978).The structure of coping. Journal of Health and Social Behavior. 22, 337-356. 
Royal College of Paediatrics and Child Health. (2001). Recognition and assessment of acute pain in children. Guidelines for Good Practice. London.

Rush, R., Rush, S., Nicolau, J., Chapman, K., \& Naqvi, M. (2004). Systemic manifestations in response to mydriasis and physical examination during screening for retinopathy of prematurity. Retina. 24(2):242-5.

Saunders, R.S., Miller, K.W., \& Hunt, H.H. (1993). Topical anesthesia during infant eye examinations: does it reduce stress? Ann Ophthalmology. 25, 436-439.

Sharek, P.J., Wayman, K., Lin, E., Strichartz, D., Sentivany-Collins, S., Good, J., Esquivel, C., Brown, M, \& Cox, K. (2006). Improved pain management inpediatric postoperative liver transplant patients using parental education and non-pharmacologic interventions. Pediatric Transplantation. 10, $172-122$.

Sinha, M., Christopher, N.C., Fenn, R., \& Reeves, L. (2006). Evaluation of nonpharmacologic methods of pain and anxiety management for laceration repair in the pediatric emergency department. Pediatrics. 117(4), 1162-1168.

Stevens, B., Gibbins, S., \& Frank, L. (2003). Treatment of pain in the neonatal intensive care unit. Pediatric Clinics of North America. 47 (3), 633-650.

Ueda, D., \& Caulfield, R. (2001). Management of medically fragile infants. Early Childhood Education. 28(4), 247-249.

Unicef. (1990). The UN convention on the rights of the child: In child friendly language. [Poster]. Available from The Royal Canadian Mounted Police Web site, http://www.rcmp-grc.gc.ca/pdfs/NCD-poster_e.pdf

Van Dijk, M. (2001). Post-operative pain assessment in neonates and infants: state of the art. Pediatric Pain. 5(4), 37-39.

Van Dijk, M., De Boer, J.B., Koot, H.M., Duivenvoorden, H.J., Passchier, J., Bouwmeester, N., \& Tibboel, D. (2001). The association between physiological and behavioral pain measures in 0 to 3 year old infants after major surgery. Journal of Pain and Symptom Management. 22 (1), 600-609.

Van Dijk, M., De Boer, J.B., Koot, H.M., Tibboel, D., Passchier, J., \& Duivenvoorden, H.J. (2000). The reliability and validity of the COMFORT scale as a post operative pain instrument in 0 to 3 year old infants. Pain. 84, 367-377.

Von Bayer, C.L., \& Spagrud, L.J. (2007). Systematic review of observational (behavioral) measures of pain for children and adolescents aged 3 to 18 years. Pain. 127, 140-150.

Warren, I. (2002). Facilitating infant adaptation: the nursery environment. Semin Neonatol. 7, 459-467.

Williamson, G.G., Zeitlin, S., \& Szczepanski, M. (1989). Coping behavior: implications for disabled infants and toddlers. Infant Mental Health Journal. 10(1), 3-13. 
Zealy, C. (2005). The benefits of infant massage: a critical review. Community Practitioner. 78(3), 98-102.

Zeitlin, S., Williamson, G.G., \& Rosenblatt, W.P. (1987). The coping with stress model: a counseling approach for families with a handicapped child. Journal of counseling and development. 64, 443466. 


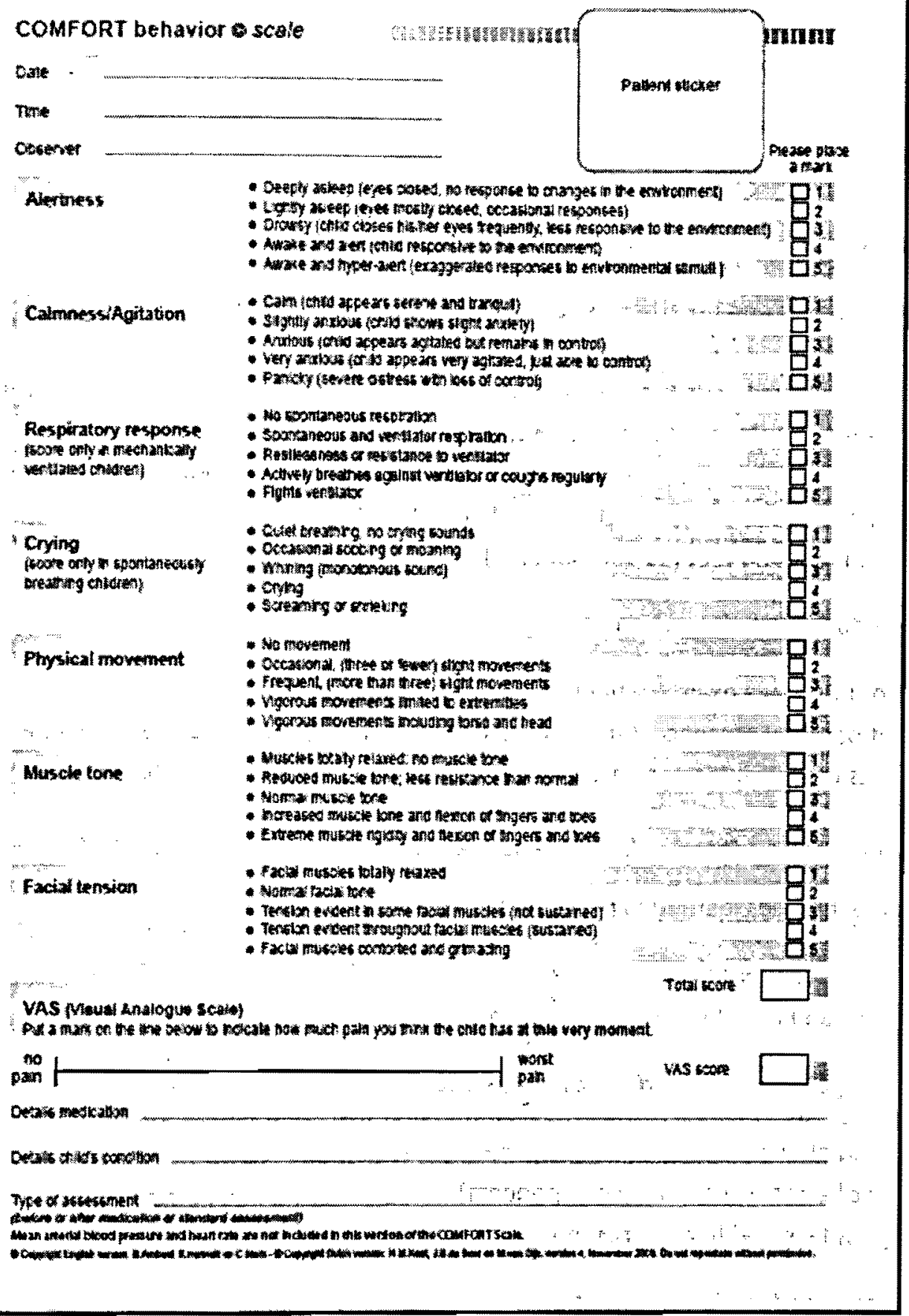


Appendix B: $\quad$ Child Life Support Sessions Outline: 3 sessions, 30 minutes each.

\section{Session 1:}

5 minutes - Introduction to comfort positions

- Step 1. Swaddling.

- Step 2. Sidelying, Supine, Prone positions for comfort.

15 minutes - Introduction to infant massage, Demonstration by CIMI (McCLure, 1989).*

- Step 1. Caregiver relaxes and breathes deeply as they prepare the baby (clothing adjusted/blankets).

- Step 2. Oils palms and rub hands together to warm.

- Step 3. Shows palms to baby, asks permission to begin.

- Step 4. Demonstration of hand containment, two areas of body are covered/swaddled by each hand (i.e. /one hand on the head, the other hand on the foot).

- Step 5. Massage of legs and feet (11 components).

10 minutes - Caregiver education/information

- Information about ROP eye exam - what happens during the exam?

- Education about parental presence during procedures, and how parents can participate and assist their infants coping; information about developmental stages of premature infants.

\section{Session 2:}

10 minutes - Review of techniques learned in previous session.

- Swaddling and positions for comfort.

- Hand containment and infant massage techniques.

15 minutes - Infant massage demonstration of new steps 5 to $7 . *$

- Step 5. Massage of abdomen (6 components).

- Step 6. Massage of arms and hands (9 components).

- Step 7. Massage of face and head (6 components).

5 minutes - Review caregiver education/information.

- Information about ROP eye exams. Answer caregiver questions/concerns.

- Education about parental presence and participation. Answer caregiver questions/concerns.

- Discuss common infant cues and developmentally appropriate caregiver responses. 


\section{Session 3:}

10 minutes - Review of techniques learned in previous sessions.

- Swaddling and positions for comfort.

- Hand containment and infant massage techniques.

15 minutes -Infant massage demonstration of new steps 8-10*.

- Step 8. Massage of the back (5 components).

- Step 9. Gentle movements (5 components).

- Step 10. A kiss to grow on!

5 minutes - Review caregiver education/information.

- Information about ROP eye exams. Answer caregiver questions/concerns.

- Education about parental presence/participation. Answer caregiver questions/concerns.

- Going over past discussion on premature infant development and cues. Answer caregiver questions/concerns.

* IMPORTANT NOTE - This touch protocol will be followed unless the infant cannot tolerate it and shows visible signs of distress. Distress includes a significant colour change, more than 30 seconds of crying; hyperextension of extremities, trunk or tongue; frantic activity, squirming, or twitching; tremoring, yawning, clenched fists or hiccoughs. (Livingstone, et al. 2007)

Direct touch may be disruptive and unbearable to the sensitivity of some infants. Sometimes hand containment, just placing one's hands over the body, and not massaging the infant, may be all that the infant can tolerate at that particular time. In cases where this happens, Hand containment will be practiced exclusively on the infant, and the CIMI will demonstrate additional infant massage techniques on the demonstration doll only. 
Appendix C. Telephone Script

Hello this is Morgan Livingstone the Certified Child Life Specialist and researcher from the Eye Clinic at Sick Kids. I am calling to explain the infant coping pilot study that Dr. Tehrani and I are conducting with babies during their ROP eye exams. David Ford, our Patient Information Coordinator, indicated that you were willing to be contacted about participating in the study.

Is this a convenient time to speak? If not I am happy to call back at a more appropriate time that better suits your schedule.

While I explain this study, you are welcome to ask me any questions you may have at any time.

The purpose of this study is to explore the effect of 3 child life support sessions on a premature baby's coping during an ROP eye exam. We want to observe and record a baby's coping during an ROP eye exam before and after the baby and their caregiver(s) have received 3 child life support sessions to see if there is an improvement in the baby's coping after the child life support sessions. The observations will be recorded on an approved checklist called the COMFORT behavior scale. Results will be used to improve the standards of best practice for premature babies coping needs during procedures.

For this study, Dr. Tehrani, the ophthalmologist, and myself, Morgan Livingstone the certified child life specialist, along with an ROP nurse and an ophthalmology fellow, will be focusing on your baby's coping during their routine ROP eye exam. Retinopathy of Prematurity (ROP) is a disease of the blood vessels that supply the blood to the inside surface of the eye, known as the retina. This pilot study will examine the existing coping process of babies undergoing ROP eye exams, and then examine the impact of three child life supportive sessions on the coping competence of the patients during future ROP eye exams. Upon consent to participate in this study, two observers will be present to assess the coping responses of the patient during their initial ROP eye exam.

After this initial exam, I will book three child life support sessions with you at times that are convenient to your schedule. These sessions will take place in your residence over the next one to two weeks before your baby's next scheduled ROP eye exam.

The three Child Life Support Sessions will include three separate sessions, each 30 minutes long. These sessions will include:

- Infant massage and touch holds

- Comfort positioning 
- Caregiver education on baby development, ROP eye exams, and parental presence and involvement during the exam.

The coping responses of your baby will then be re-assessed by the same two observers during the next scheduled ROP eye exam.

There are no costs to your family for participating in this study. If you chose to participate in this study, you will receive infant massage oil, informative sheets about the study, and a blanket for your baby. Upon completion of the study, you will receive a participation certificate.

There are potential benefits for the families participating. We expect that babies will have significantly less distress and increased coping during examinations; this may provide for easier examinations. We also expect that most caregivers will gain knowledge and skills that increase their ability to support their baby before and after examination, thus improving the patients coping responses to invasive procedures and reducing stress.

There are also potential benefits to society. Future research based on this pilot study will likely show child life techniques provide significant support for babies and their caregivers, undergoing repetitive, painful, invasive medical procedures.

To ensure confidentiality, all the information we collect for this study will be reported in summery format and you, your baby and any personal information will not be identified. Access to your personal information will be strictly limited to members of the research team and the clinical research monitors. Upon arrival for your baby's initial exam, our ROP nurse Beverley Griffiths will go over the consent form and confidentiality with you before you agree to participate in the study.

Please feel free to contact me with any questions you may have with regards to this study. I can be reached at $416893-2249$. 
Appendix D:

SickKids
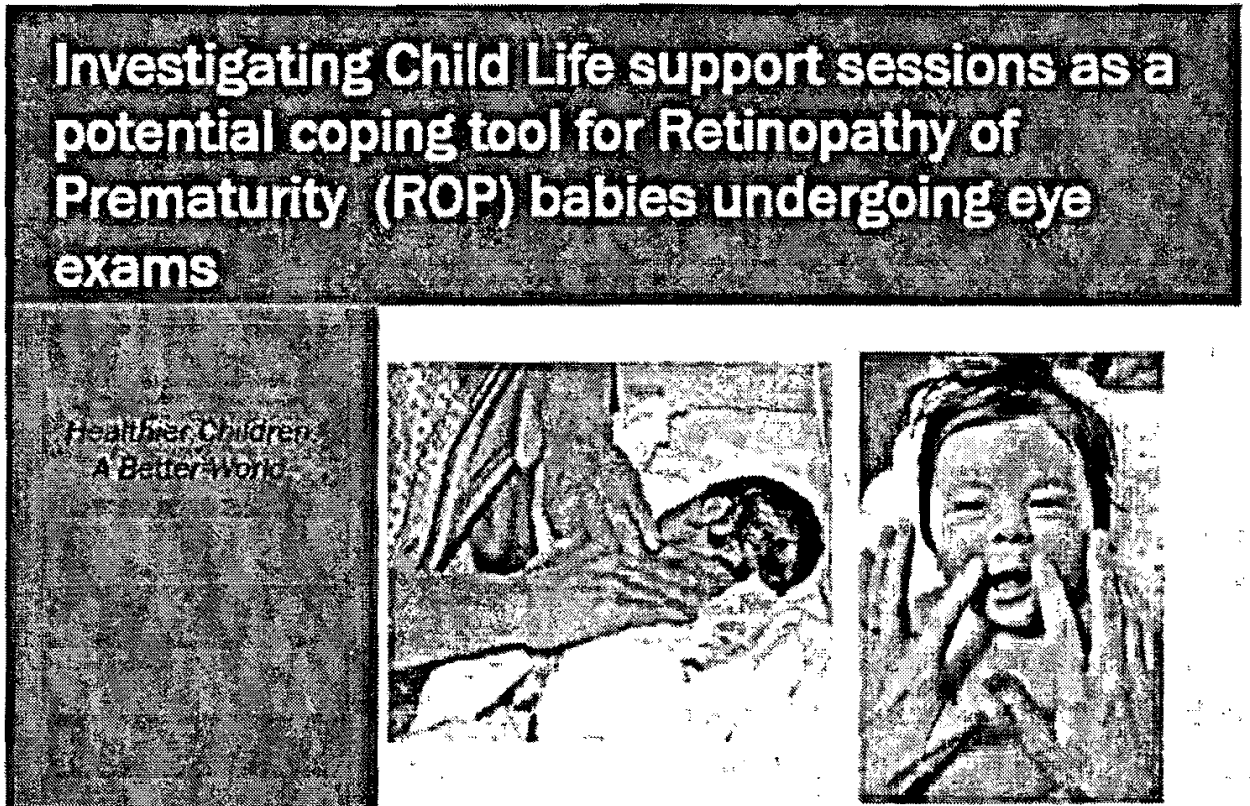

Fetnopethy of Premuturiy (rop) is disewse of the blcod vessels that supply the blood to the insice surfuce of the eye, known as the retana. This pitot study will exwmine the existing coping process of

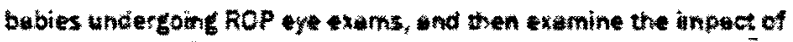
three child ate supporive sessions on the coping competefoe of the putents daring future kOP eye ands.

This research hopes to prove that the child life support sessions provided to babses and partass wintincrease und improve coping responses of patients during paintul procedures.

Ey doing 5o, the hop is to dheviate, eiminate and woid potentialy hurntul negative coping responses and prevent porentiol coping probsems in future heathy desclopment of the buby.

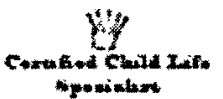


What wil twke piace durine this skudy.

Upen cowsent to porstipule in this study, awo observers will be present to assess the coping responses of the patient durng their thitial ROP eje exsrm.

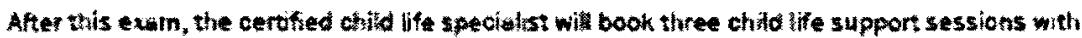

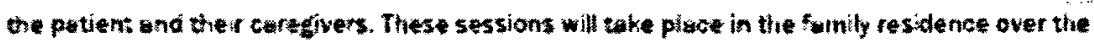
next one wo wo waks betore the nex: scheduled hop eye exam.

The three Child Life Support Sessions wil unciwae three sepurste sessions, exch 30 minutes long. There sessions will indude:

- Intan massoge and touth hoids

- Colnfor positionts

- Caregiver educuton on boby ceveiopinent, ROP eye exarns, and purentul presente und invorvetnent auring the exsm.

The coping responses of the putient wat then be te ssexsed by the sune tmo observers durine the now scheduled Ro? eye exam.

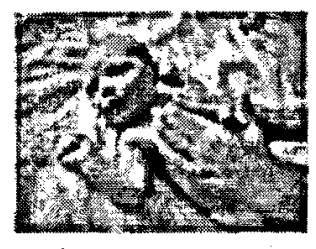

The potential benefirs to participwnts:

We expect thet bobes will have signticunty less cistress and inctetsed coping during exarnin uons: this moy provide for ensiec examinatons. We dso expect thut most coregvers will goin

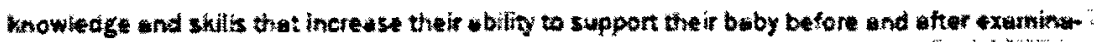
bon, thus improving the petients coping responses to invesive procedures and reduding stress. The potential be whefts to society

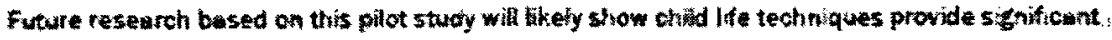
support for bubies and the curegivers, undergoing repettove, puinful, mvesive medical procecures.

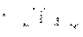


Appendix E.

\section{SickKids}

THE HOSPITAL FOR

SICK CHI LDREN

Research Ethics Board

Research Ethics Board

\section{Research Consent Form}

Title of Research Project:

- Pilot Study: Investigating Child Life support sessions as a coping tool for Retinopathy of Prematurity infants undergoing ROP eye exams.

\section{Investigator(s):}

- Dr. Nasrin Tehrani (Principal Investigator): 416 582-8492 (pager)

- Morgan Livingstone CCLS CIMI (Co-investigator): 416 893-2249

Purpose of the Research:

\section{INTRODUCTION}

A Certified Child Life Specialist (CCLS) is an expert in child development that promotes effective coping in infants and children facing challenging experiences, particularly those related to healthcare and hospitalization. Understanding that the wellbeing of an infant depends on the support of the family, a CCLS also provides information, support and guidance to caregivers. Many CCLS's are certified as Infant Massage Instructors (CIMI), and can teach caregivers how to provide gentle soothing touch techniques to premature infants. 
Retinopathy of Prematurity (ROP) is a condition that can occur in some premature babies when blood vessels and scar tissue grow over the retina, which is the back of the eye. ROP can affect an infant's vision. An ophthalmologist can detect ROP during an eye exam.

\section{WHY IS THIS STUDY BEING DONE?}

This study explores the effect of 3 child life support sessions on a premature infant's coping during an ROP eye exam. We want to observe and record an infant's coping during an ROP eye exam before and after the infant and their caregiver(s) have received 3 child life support sessions to see if there is an improvement in the infant's coping after the child life support sessions. The observations will be recorded on an approved checklist called the COMFORT behavior scale. Results will be used to improve the standards of best practice for premature infants coping needs during procedures.

\section{HOW MANY PEOPLE WILL TAKE PART IN THIS STUDY?}

20 infants and their caregivers will be invited to participate.

\section{WHAT IS INVOLVED IN THE STUDY?}

Infants and their caregivers that are referred to the Hospital for Sick Children (HSC) and are scheduled for an initial ROP eye exam will be asked by a staff member in the Eye Clinic if they would be willing to participate in this study, and if they are willing to be contacted by a researcher. A prepared informative letter about this study will be given to each caregiver at that time or mailed to their residence. By phone a researcher will explain the reasons for the study, describe the child life support sessions, and answer any questions about the study. If a parent chooses to join the study, they will complete a consent form on or before the day of their infants ROP exam. 
The infant's coping will be observed and recorded on a short checklist during the initial ROP eye exam by 2 observers: 1 nurse and 1 fellow. Caregivers will be invited to book 3 child life support sessions with the certified child life specialist over the next 1-2 weeks. These sessions are to take place at a time that bests suits the caregiver's schedule. The support sessions will take place in the family residence, and all supplies associated with the session will be provided by the child life specialist at no cost to the caregivers.

During the 3 support sessions the CCLS will teach the caregivers positions that they can place the infant in that promote comfort, teach various infant massage strokes to help the infant relax, and provide information about the ROP exam, infant development, and will explain how parents being present during the exam can help the infant cope better.

During the follow-up ROP eye exam, the infants' coping will be observed and recorded again by the same observers.

\section{WHAT ARE THE RISKS OF THE STUDY?}

We know of no harm that taking part in this study could cause you or your infant.

\section{WHAT ARE THE BENEFITS OF PARTICIPATING IN THE STUDY?}

We expect that the infant will have significantly less distress and show improved coping during examinations; this may provide for easier examinations. We also expect that most caregivers will gain both knowledge and skills that increase their ability to support their infant before and after examination, thus improving infant coping with procedures and reducing infant stress. From this, caregivers can understand the basics of ROP and the ROP exam, ask better questions of the doctors and nurses, and reduce the infants stress during treatment. 


\section{WHAT ARE THE BENEFITS TO SOCIETY?}

Future research based on this pilot study will likely show child life techniques provide significant support for infants and their parents, while those infants undergo repetitive, painful, invasive medical procedures

\section{WHAT OTHER OPTIONS ARE THERE?}

Taking part in this study is voluntary. Caregivers may say no to this study, or leave the study at any time. Saying no or leaving the study does not affect your infant's treatment in any way. No infant will receive an ROP eye exam for the purpose of this study.

\section{WHAT ABOUT CONFIDENTIALITY?}

Infants recorded assessments are strictly confidential. No personal information will be presented at meetings, published, or released without your written consent unless required by law. HSC study records will be kept in a secure, locked office. Research records with your name on them may be inspected by the HSC Clinical Research Office Monitor.

\section{WILL I BE PAID TO TAKE PART IN THIS STUDY?}

There is no payment for participation.

\section{WHAT ARE THE COSTS?}

There are no costs to you if you take part in this study.

\section{WHAT ARE MY RIGHTS AS A PARTICIPANT?}

You may say no to this study, or you may choose to leave the study at any time. Signing 
this consent does not waive your legal rights. Nor does it relieve the investigators and institutions from their legal and professional responsibilities. For further information on these rights, contact the Sick Kids Research Ethics Manager at 416-813-5718.

\section{CONFIDENTIALITY:}

We will respect your privacy. No information about who your child is will be given to anyone or be published without your permission, unless required by law. For example, the law could make us give information about you if a child has been abused, if you have an illness that could spread to others, if you or someone else talks about suicide (killing themselves), or if the court orders us to give them the study papers.

Sick Kids Clinical Research Monitors, employees of the funder or sponsor, or the regulator of the study may see your child's health record to check on the study. By signing this consent form, you agree to let these people look at your records. We will put a copy of this research consent form in your child's health record and give you a copy as well.

The data produced from this study will be stored in a secure, locked location. Only members of the research team (and maybe those individuals described above) will have access to the data. This could include external research team members. Following completion of the research study the data will be kept as long as required then destroyed as required by Sick Kids policy. Published study results will not reveal your child's identity.

\section{CONFLICT OF INTEREST:}

All research team members have no conflict of interest to declare.

\section{CONSENT:}

"By signing this form, I agree that:

1) You have explained this study to me. You have answered all my questions:

2) You have explained the possible harms and benefits (if any) of this study. 
3) I know what I could do instead of having my child take part in this study. I understand that I have the right to refuse to let my child take part in the study. I also have the right to take my child out of the study at any time. My decision about my child taking part in the study will not affect my child's health care at Sick Kids.

4) I am free now, and in the future, to ask questions about the study.

5) I have been told that my child's medical records will be kept private except as described to me.

6) I understand that no information about my child will be given to anyone or be published without first asking my permission.

7) I agree, or consent, that my child may take part in this study."

Printed Name of Parent/Legal Guardian Parent/Legal Guardian's signature \& date

Printed Name of person who explained consent Signature of Person who explained consent \& date

Printed Witness' name (if the parent/legal guardianWitness' signature \& date does not read English) 
THE HOSPITAL FOR

SICK CHILDREN

Research Ethics Board

If you have any questions about this study, please call Graduate Student Researcher Morgan Livingstone (416)893-2249.

Ryerson Graduate Student Supervisor, Pat Corson (416) 979-5000 x7637.

If you have questions about your rights as a subject in a study or injuries during a study, please call the Sick Kids Research Ethics Manager at 416-813-5718. 


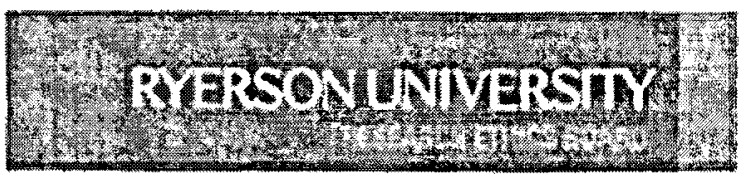

Ta: Mongan Livingsione

Re: REO 200*-108: Pilot Study: Investggating Chid Life Support seswions as a cuping hol tor fetitwpathy of prematurity (ROP) infants undergoing RoP eye exans.

Date: Luly 28, 2008

Dear Morean Livingstonc,

The neview of your pratcol REB file RID $2008-198$ is now complat. The projox has bon approved ro a one year period. Please note that before proceding with your protect compliance

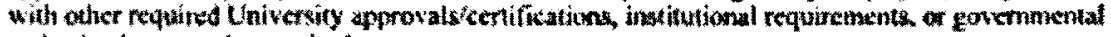
wuthorizstivas may be nequirod.

This aporoval may be extended after one year copon nequex. Pletase be ajvised that if the project is not renewed, approval will expite and no more rescarch involving humans may take place. If this is a funded projext, woss to resereh funds ma slow be affected.

Hease note that KFA aproval policies require that you where stricty to the protocol as last nevicued by the REQ and than any modifications must be apowed by the Boad before they can he

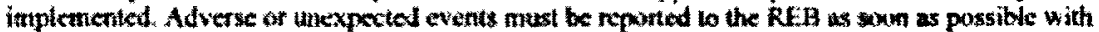
an indication from the Primipal Imyesigator as to how, in the view of the Principal Investigator. these events affect the contuntertin of the prowocol.

Finally, if research sabjexts are in the care of health facilny. at a school, or wher institulion of

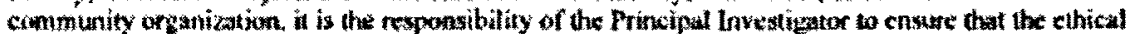
cruidelines and approtals of tho folitics or insatutions are oblained and fied with the RER prior to the initiaton of any neseanth. -in. $4 . .$.

Please qawote your RTB lile number (RFA 2008-198) on tuate correxpondcace.

Cragratulations and hest of fuck in conducting your rosearch.

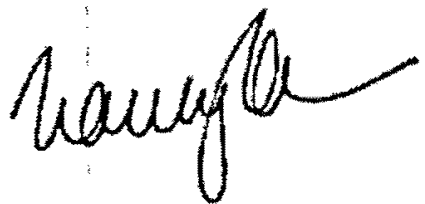

Nancy Willon. Who.

Chair, Rescarth Ethics Buard 


\section{Kids Research Ethics Board (REB)}

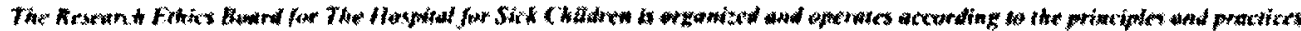

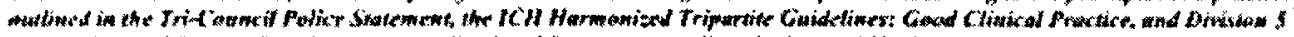

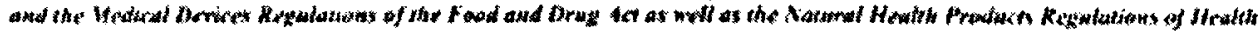

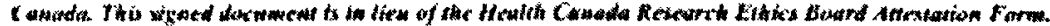

\section{Approval \& Terms of Agrement}

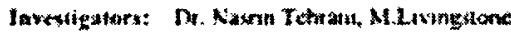

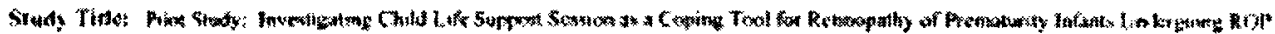
Eye f.imox.

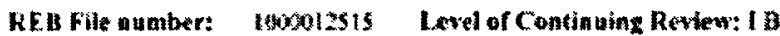

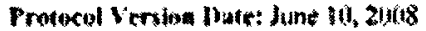

Coaxem \& Axkat Form Verwion Date(s) Consent Form - July 11, 2008

Invertioviter's Brechare V́crilon Date; NiA

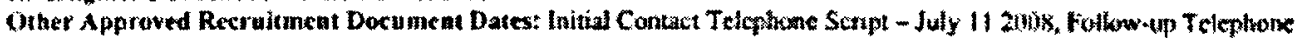
Srtip - luty $1120 \mathrm{~ns}$

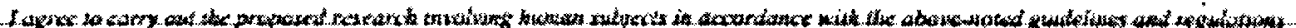

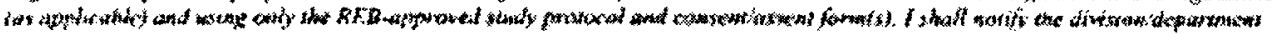

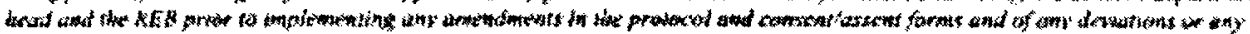

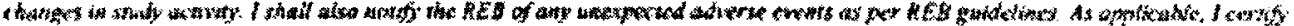

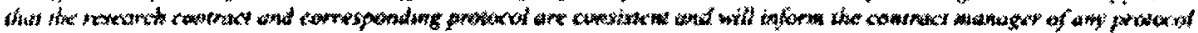

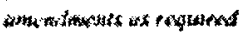

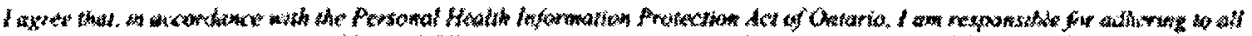

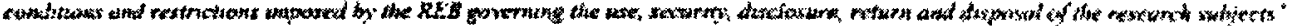

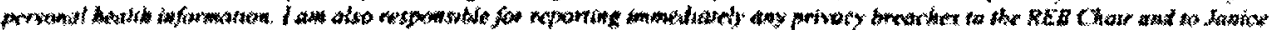

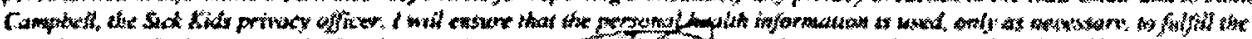

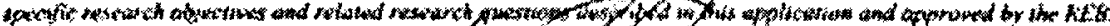

Sigustore al Principal Investigusar

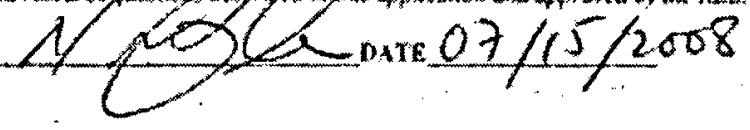

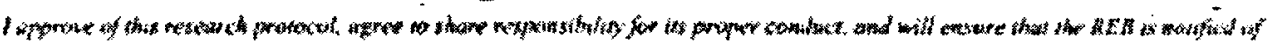

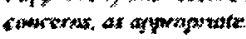

Signature of Divizicumepurtraemt lead

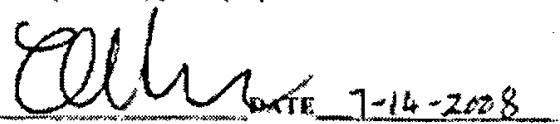

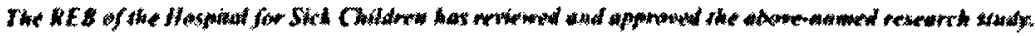

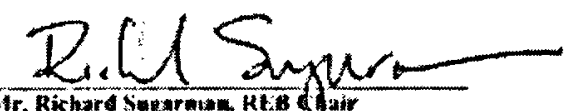

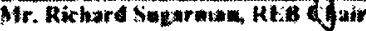

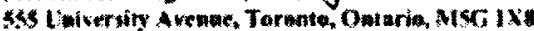

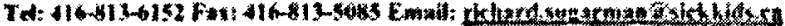

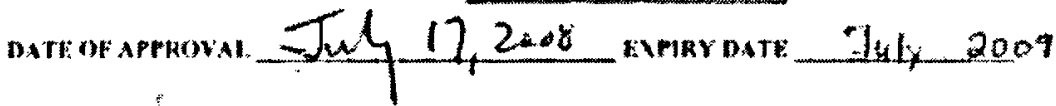

